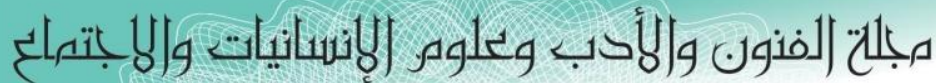
Journal of Arts, Literature, Humanities and Social Sciences

\title{
أثز استخدام انموذج رايجلوث في اكتساب المفاهيم العلمية لاى طالبات الخامس العلمي الاحيائي في مادة إدئي علم الاحياء
}

م.م. و ولاء داخل كطقان المديرية العامة لتربية القادسية-القادسية- العرلق

م.م. منان كعيم غازي المديرية العامة لتربية القادسية_القادسيةـ العراق

استهدف البحث التحقق من الفرضية الصفرية الآتية:- ليس هنالك فرق ذو دلالة إحصائية عند مستوة (0.05) بين متوسط درجات الطالبات اللو اتي درُسن بأستعمال نموذج (ر ايجلوث) ومنوسط درجات الطالبات اللواتي ذُرسن بالطريقة الأعتيادية ولتحقيق هدف البحث اختارت الباحثنان عينة عشوائية من اعدادية الطليعة للبنات في الديو انية بلغ حجمها (52) طالبة واستبعدت طالبنان فأصحت (50) طالبة بواقع (25) لكل من المجموعتين التجريبية والضابطة، واعدت الباحثتان اختبار لاكتساب المفاهيم العلمية وتحثث من صدقه وثباته ومعامل الصعوبة و التمييز لفقراته و أظهرت المعالجة الأحصائية بأستخدام الأختبار التائي (T- test) تفوق المجموعة التجريبية التي درست على وفق انموذج (رايجلوث) على الضابطة التي درست بالطريقة الاعتبادية وفي ضوء نتائج البحث اوصت الباحثتين بتوصيات عدة منها:ضرورة تدريب مدرسين علم الأحياء على كيفية استخدام انموذج (رايجلوث) من خلال دور ات تدريبية تطويرية واعنماد انموذج (رايجلوث) في تدريس علم الأحياء نظر اً لما يتمتع فيه من كفاية من تحقيق الأهداف التعليمية فضلاً عن ذلك فق اقترحت الباحثتين استعمال انموذج (رايجلوث) في اكتساب المفاهيم العملية في مو اد أخرى. 


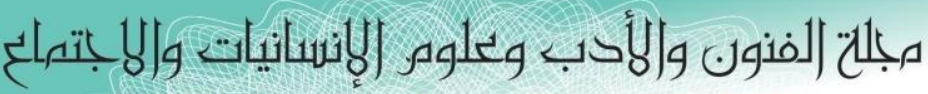
Journal of Arts, Literature, Humanities and Social Sciences

ISSN online: 2414 - 3383

ISSN print: 2616 - 3810

Volume (46)

(46) (4) (العدد)

December 2019

\title{
The Effect of Using Rigloth Model on Acquisition of Scientific Concepts among Fifth Biological Students in Biology
}

\begin{abstract}
The research aimed to verify the following zero hypothesis: - There is no statistically significant difference at the level (0.05) between the average scores of students studied using the model (Rigloth) and the average scores of students who were studied in the usual way. Diwaniya reached (52) students and excluded two students and became (50) students (25) for each of the experimental and control groups, and the researchers prepared a test to acquire scientific concepts and urge honesty and stability and the difficulty and discrimination coefficient of its paragraphs and showed statistical treatment using the test $\mathrm{T}$ - test The experimental group studied according to the Rigeloth model outweighed the officer who studied in the usual way. In the light of the research results, the researcher recommended several recommendations, including:

The need to train biology teachers on how to use the model (Reigloth) through developmental training courses and the adoption of the model (Reigloth) in the teaching of biology because of its sufficient to achieve educational objectives, in addition, the researcher suggested the use of the model (Reigloth) in the acquisition of concepts Operation in other materials.
\end{abstract}




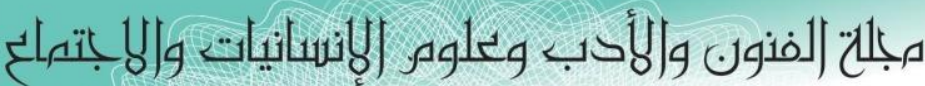

Journal of Arts, Literature, Humanities and Social Sciences

ISSN online: 2414 - $3383 \quad 2019$ ديسمة 2616

ISSN print: $\mathbf{2 6 1 6}-\mathbf{3 8 1 0}$

Volume (46)

العدد (46)

December 2019

1-مشكلة البحث: Problem of the research: يؤكد التربويون وجود عدة مشاكل تشغل جميع من له له

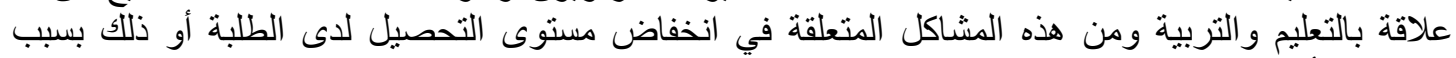

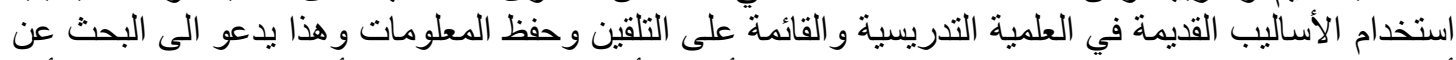

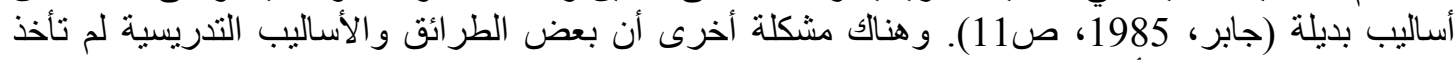

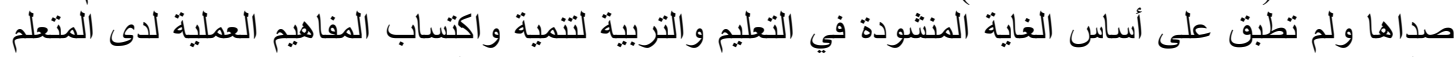

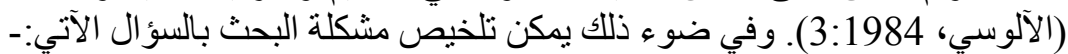

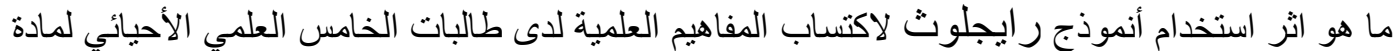

علم الأحباء؟

2-2 أهمية البحث: Importance and need of the research:

وتتخذ أهمية الدر اسة ما يلي:-

- تهدف هذه الدر اسة الى تفصيلها للاور الذي مكن ان تسهم به انموذج رايجلوث في تحقيق تعلم افضل للمفاهيم العميلة لدى الطلبة وتحسن أدائهم لعمليات التعلم.

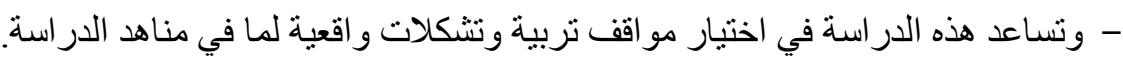

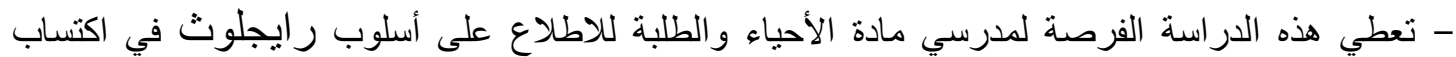

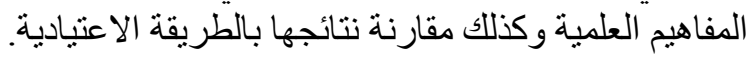

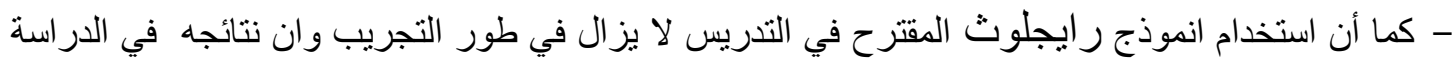

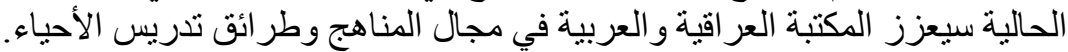

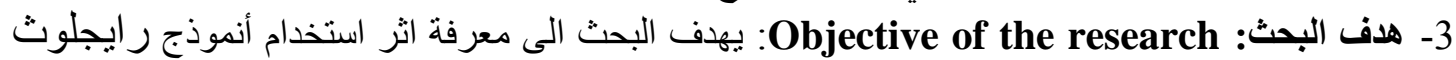
في اكتساب المفاهيم العلمية لدى طالبات الخامس العلمي في مادة الأحياء وذلك من خلال التحقق من الفرضية الآتية:

ليس هنالك فرق ذو دلالة إحصائية عند مستوى (0.05) بين متوسط درجات الطالبات اللاتي درسن باستخدام

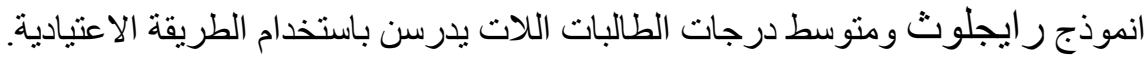

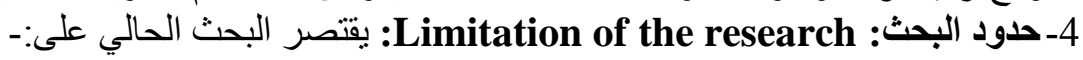
- طالبات الخامس العلمي في اعدادية الطليعة للبنات في الديو انية.

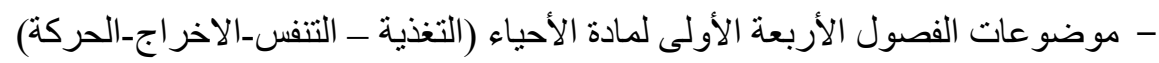

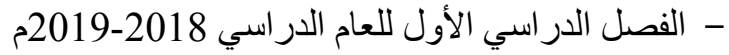
5-تعريف المصطلحات: Definition of the terms

اولاً: الأنموذج التعليمي: Teaching model

تعريف كلاوسماير (Klausmeir, 1988)

(انه خطة محكمة ومنظمة لتوظيف حكات متتابعة أو متسلسلة يتبعها المدرس تحكمها عدة عوامل داخلية

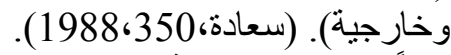

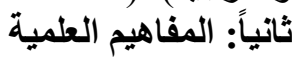

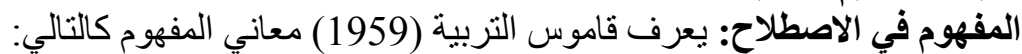

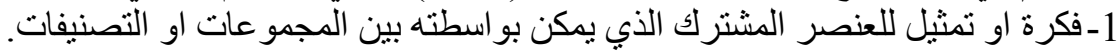

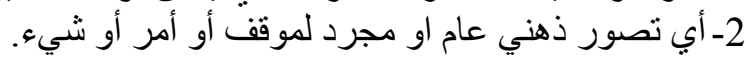
3-فكرة او رأي او صورة ذهنية (مجلة العلوم الإنسانية و الاجتماعية_العدد الثامن: 2012). 


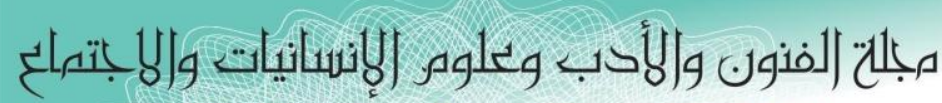
Journal of Arts, Literature, Humanities and Social Sciences

ISSN online: 2414 - 3383

ديسمبر 2019

ISSN print: 2616 - 3810

Volume (46)

العدد (46)

December 2019

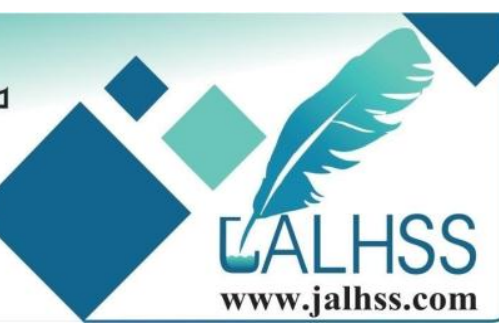

\author{
الفصل الثاني \\ جوانب نظرية ودر اسات سابقة
}

اولاً:- جوانب نظرية: Theoretical sides

أـ أنموذج رايجلوث: Reigeluth model

طور رايجلوث النظرية التوسعية لأنها تعتبر أساس تنظيم المحتوى التعليمي على المستوى الموسع

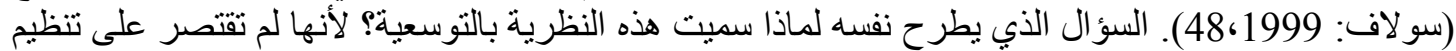

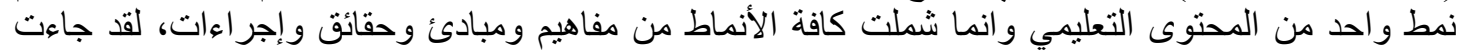
نظرية رايجلوث على ثناث نماذجي:-

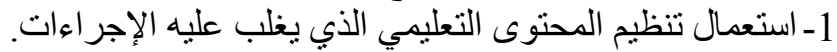

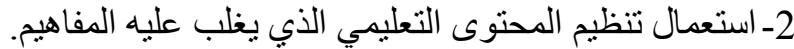

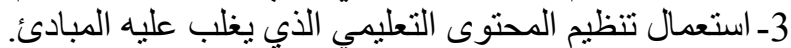

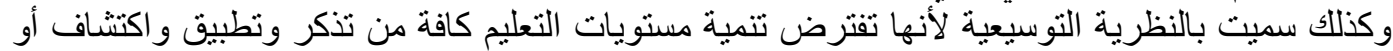
تذكر و استيعاب وتطبيق وتحليل وتركيب وتقويم منه وجهة نظر بليوم (دروزه:

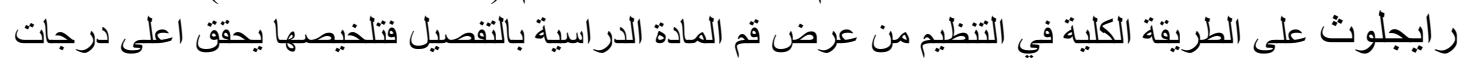

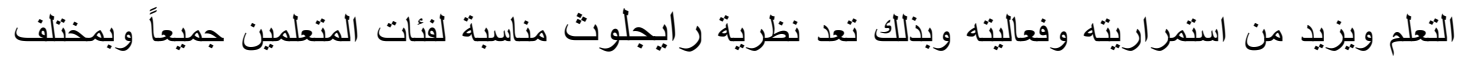
قدر اتهم العالية و المتوسطة والضعيفة وهذا يؤدي الى بقاء المادة الدراسية ورفع الدفع لدى المتعلمين (قطامي:

. (429،2000

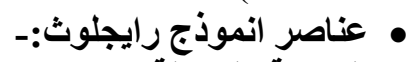

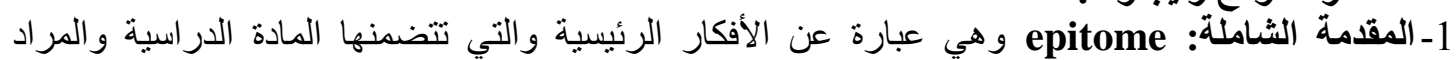

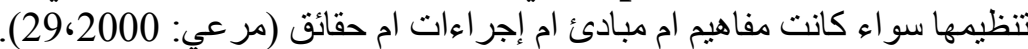

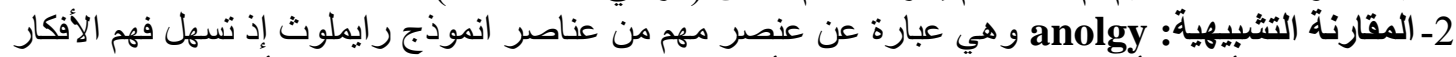

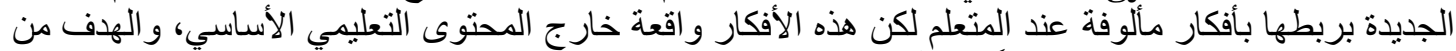

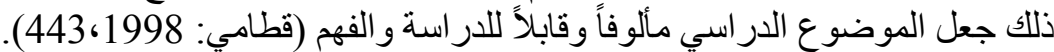

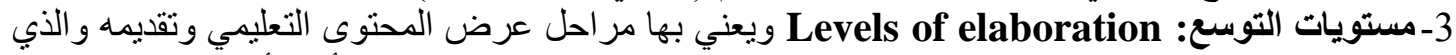

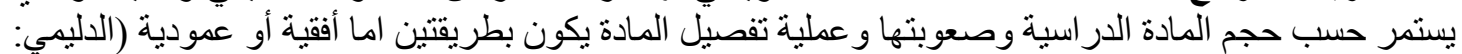
4- التلخيص: Summar zatio وهو عرض موجز لأهم الأفكار الواردة في محتوى المادة الدراسية بطريقة

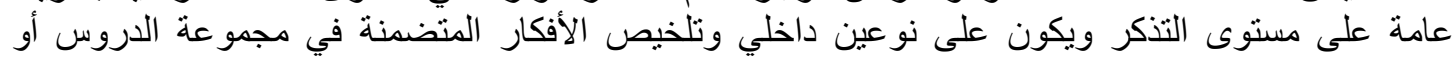

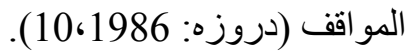

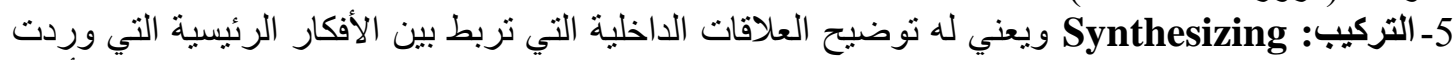

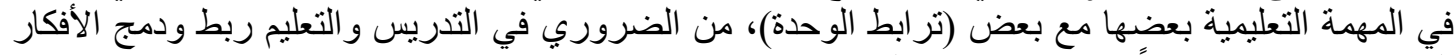

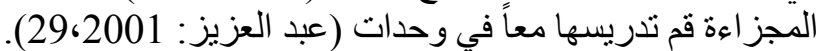
6- تحكم المتعلم: Learner control ويقصد بـ به حرية المتعلم للقيام بعملية الاختيار و التتابع بأي مما يلي: - خيط المحتوى الذي بر اد تعلمه.

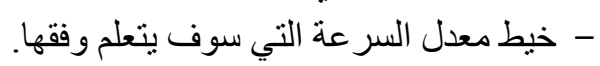

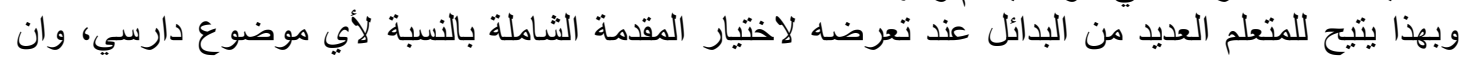

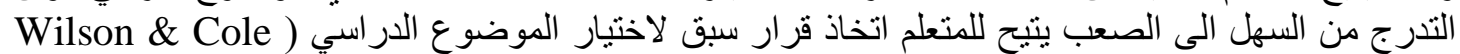

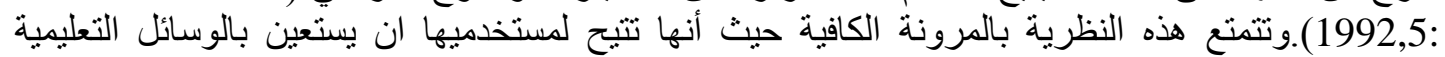

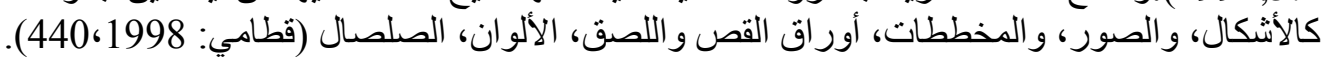




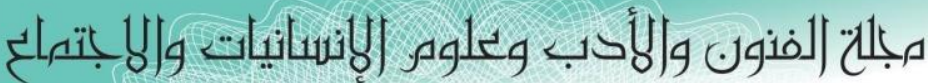

Journal of Arts, Literature, Humanities and Social Sciences

ISSN online: 2414 - 3383 ديسمبر 2019

ISSN print: $\mathbf{2 6 1 6}-\mathbf{3 8 1 0}$

Volume (46)

العدد (46)

December 2019

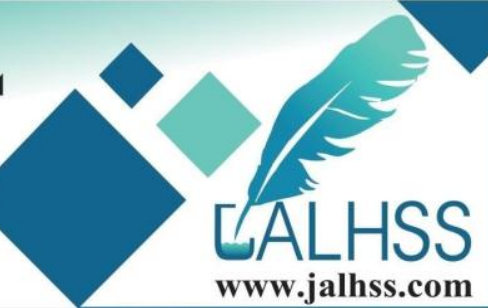

• افتراضات النظرية التوسيعية: وتتحدد افتر اضات النظرية التوسيعية على النحو الآتي:

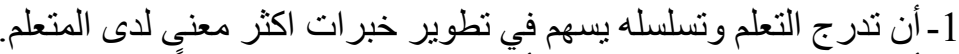

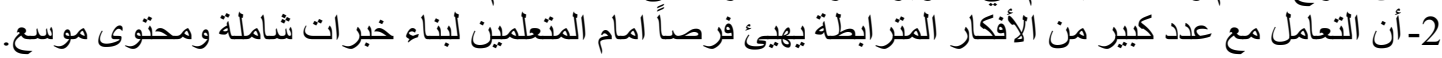

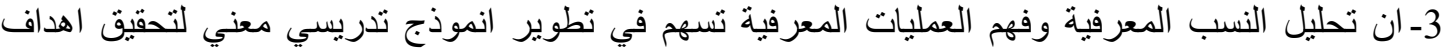

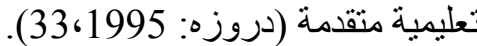

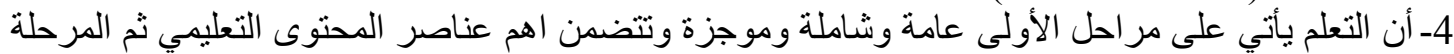
الثانية يبدأ المدرس بالتفصيل والتيل التوسع في هذه العناصر مع مر اعاة عملية الربط بين كل مرحلة تعليمية والأخرى التي تسبقها أو تلبها.

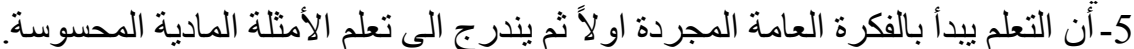

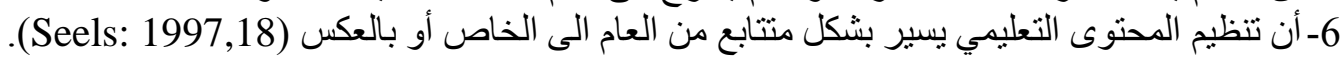

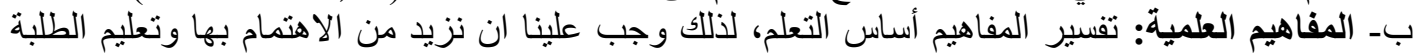

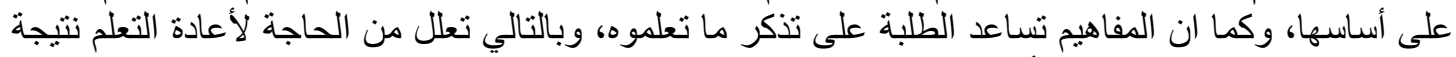

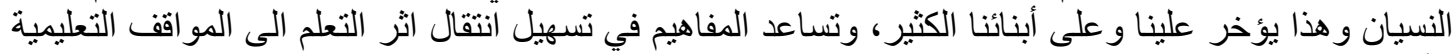

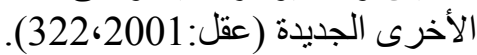
• بعض خصائص المفاهيم العلمية:

1 - تتدرج المفاهيم العلمية بصعوبتها بطريقة هرمية من صف الى الى الصف الذي يليه ومن مرحلة الى مرحلة تليها. 2- 2 - 1-تضنمن المفهوم العلمي التعميم.

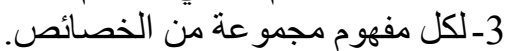

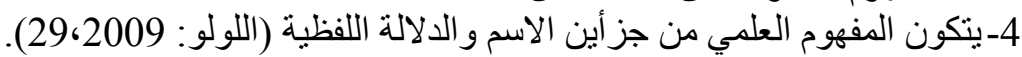

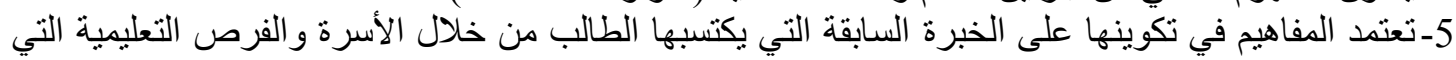

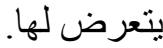

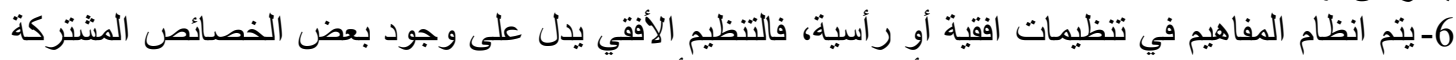
ولكن نظر لاختلافها في بعض الصفات الكفات فيأتي هنا التنظيم الر أسي.

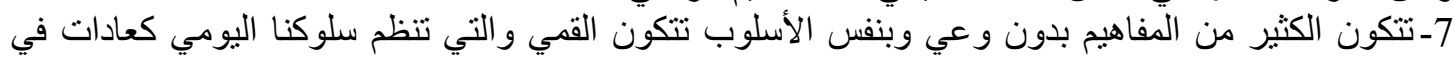
طفولتنا. 8-ستغير المفاهيم من البسيط الى المقعد ومن المحسوس الى المجرد (بطرس: 2008،56). • أهمية تلدريس المفاهيم العلمية.

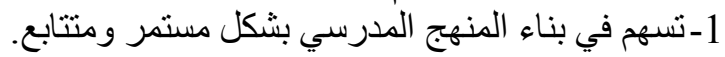

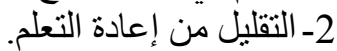
3-تنظيم الخبرة العقلية. 4- تعتبر من أدو ات التفكير و الاستقصاء الأساسية في المنهج المدرسي (سعادة: 2011،266).

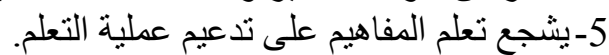

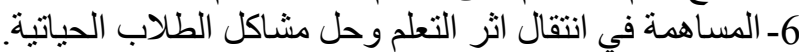

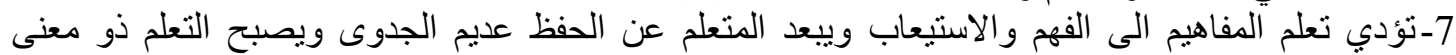

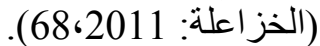
• الأسس والقواعد التي تساعد على تنمية المفاهيم.

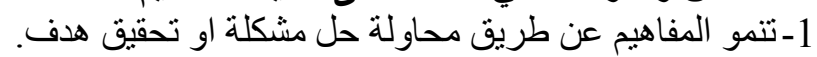
3- تتمو المفاهيم عن طريق الاكتشاف و التجريب ولثيب و الملاحظة.

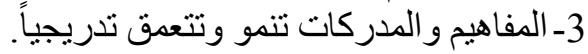

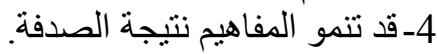
5ـ الددركات و المفاهيم لا تتمو بالأمر و لا بالتعليمات بل تحتاج لمشارجة إيجابية من الفرد وتفاعل بينه وبين البيئة 6- تنمو المفاهيم عن طريق التحليل والتمييز و التعبير (كوجك: 182،2006) 


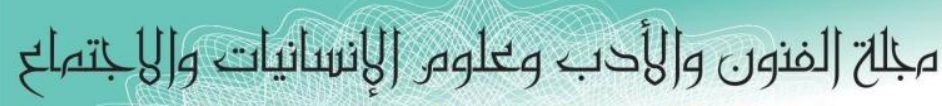
Journal of Arts, Literature, Humanities and Social Sciences

ISSN online: 2414 - 3383

ISSN print: $\mathbf{2 6 1 6}-\mathbf{3 8 1 0}$

\section{9 ديسمبر \\ Volume (46)}

العدد (46)

December 2019

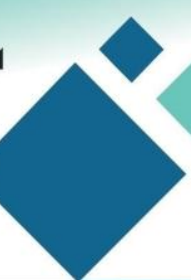

LALHSS WWw.jalhss.com

Previous studies ثانياً:- دراسات سابقة الاولة درابة

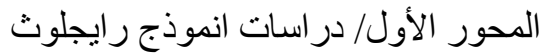

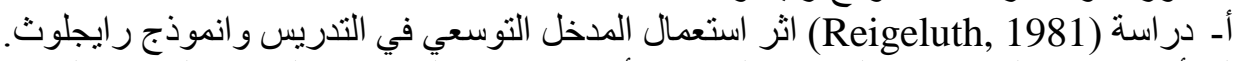

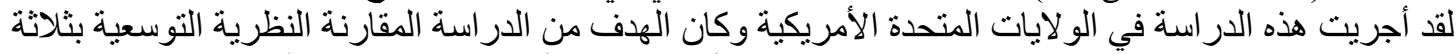

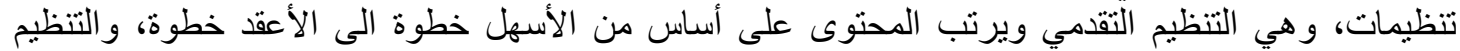

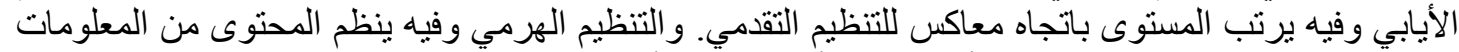

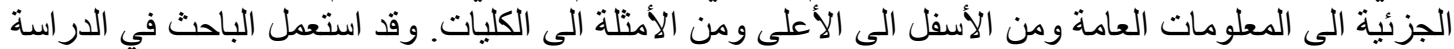

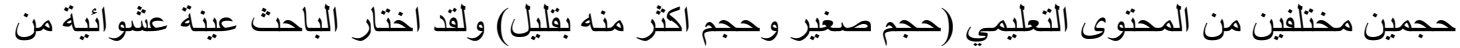

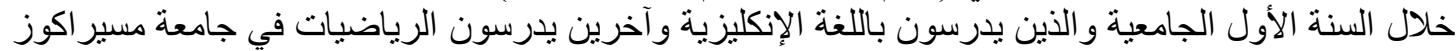

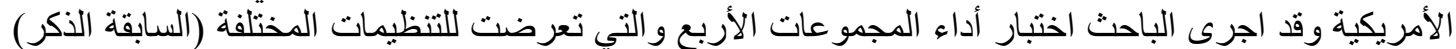

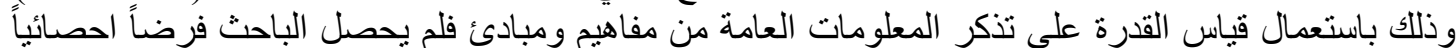

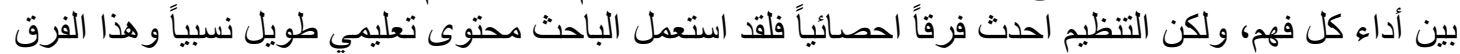

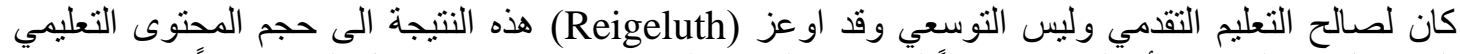

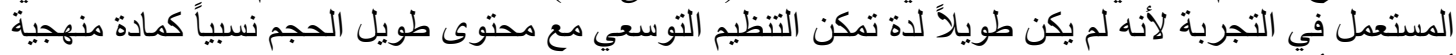

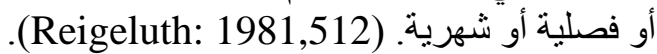
المحور الثاني/ دراسات المفاهيم العلمية.

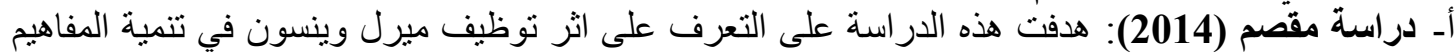

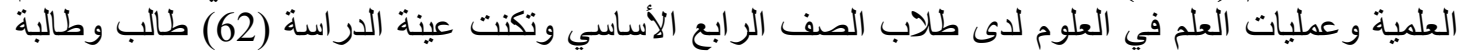

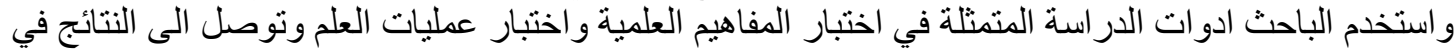

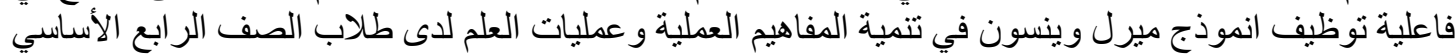

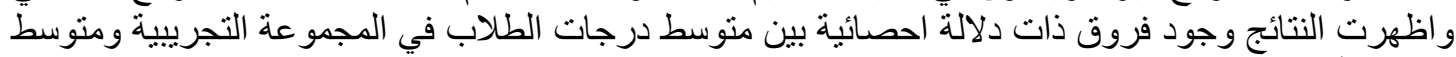

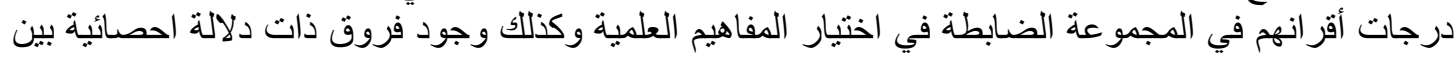
متوسط درجات الطلاب في المجموعة التجرييية ومتوسط درجات القرانية الهم في المجمو عة الضابطة في اختبار

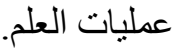

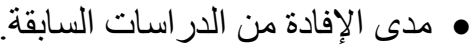
1- ان التطرق للإر اسات السابقة لا يعني الوقوف عند حدٍ ما فالعلم بعيش حالة التطور العلمي المستمر للبحث العلمي. 2ـ كانت مجتمعات الدر اسات السابقة مختلفة وبحسب هدف الدر اسة و الإجر اءات المتبعة وكذلك اختلاف طبيعة

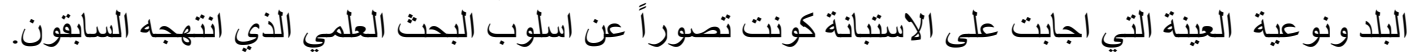

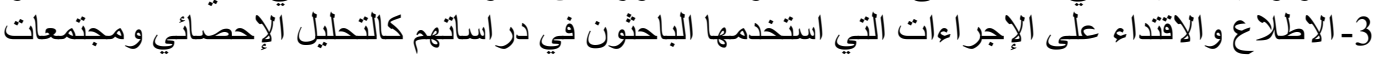

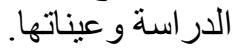

4- تحليل الاستبانة وكيفية استخلاص النتائج و الإلمام بالوسائل الإحصائية اللازمة للتحليل.

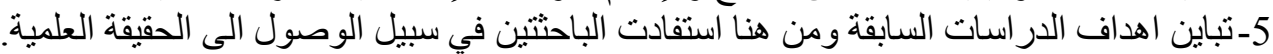

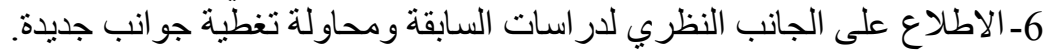

\section{الفصل الثالث}

\section{Procedures of the Research اجمراءات البحث}

يتضمن هذا الفصل عرضاً لإجر اءات البحث كما يلي: البهري: اولاً:- التصميم التجريبي: Experimental Design: يمكن تعريف التصميم التجريبي هو مخطط وبر وبرنامج

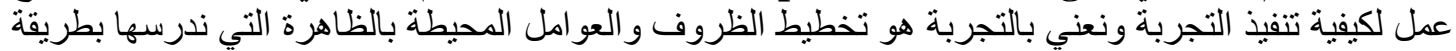

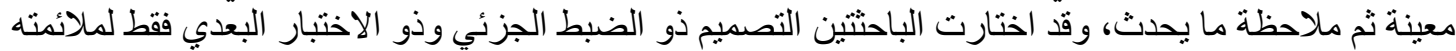

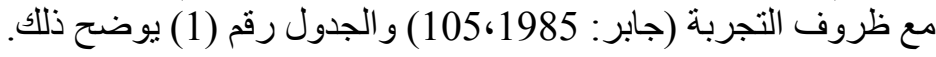




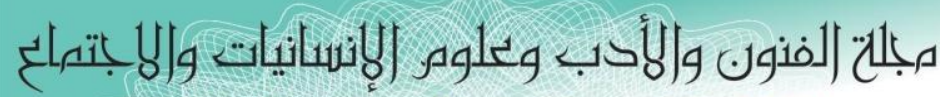
Journal of Arts, Literature, Humanities and Social Sciences

ISSN online: 2414 - 3383

ISSN print: $\mathbf{2 6 1 6}-\mathbf{3 8 1 0}$

2019 ديسمبر Volume (46)
(46) العدد

December 2019

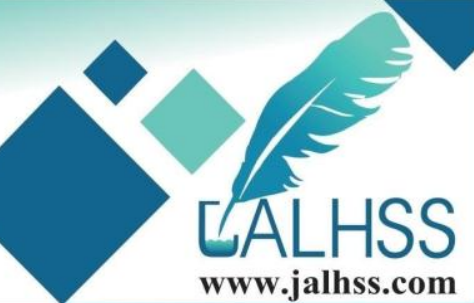

www.jalhss.com

جلول رقم (1) التصميم التجريبي المعتمد في البحث

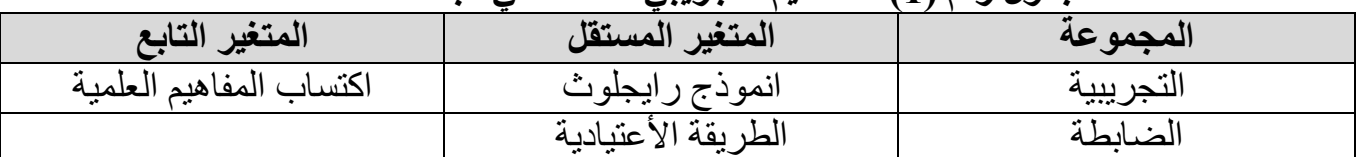

ثنانياً:- تحديد مجتمع البحث وعينته Research population and samples: بستعمل مجتمع البحث طالبات الصف الخامس العملي الأحيائي في اعدادية الطليعة للبنات في الديو انية للعام الدراسي (2018-2019م)

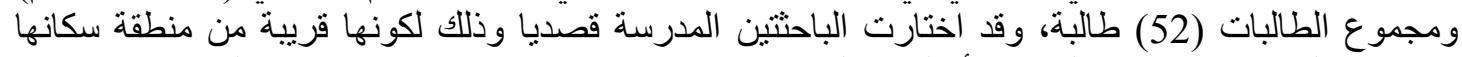

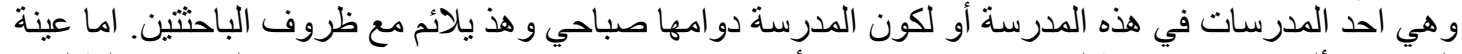

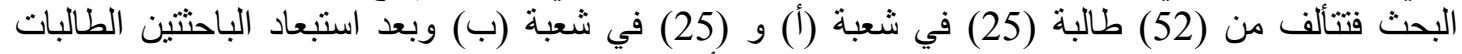

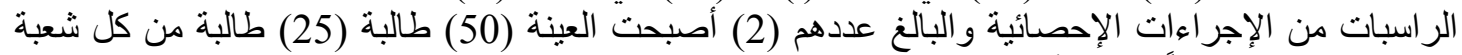

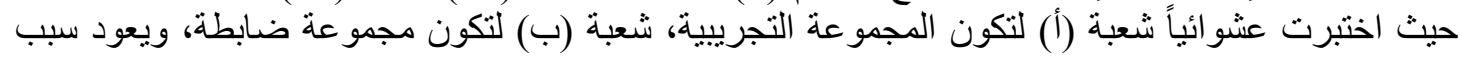

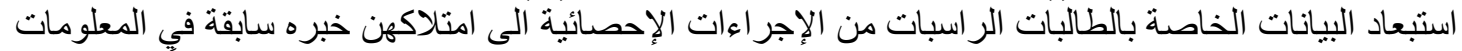

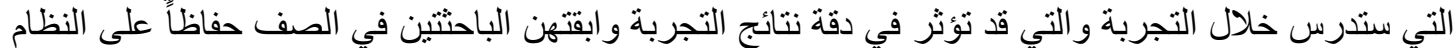
الدر اسي و الجدول رقم (2) يوضح ذلان ولتك

جدول رقم (2) توزيع عينة طالبات اعدادية الطليعة للبنات الى مجموعتين تجريبية وضابطة

\begin{tabular}{|c|c|c|c|c|}
\hline عدد الطالبات بعد & عدالد الطالبات & عدد الطالبات قبل الاستبعاد & الشعبة & المجموعة \\
\hline 25 & 1 & 26 & i & التجريبية \\
\hline 25 & 1 & 26 & ب ب & الضابطة \\
\hline 50 & 2 & 52 & & المجموع \\
\hline
\end{tabular}

ثالثاً:- تكافؤ مجموعتي البحث: Research Groups Equivalent

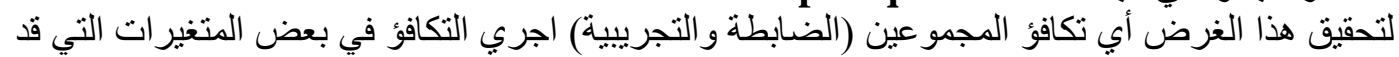

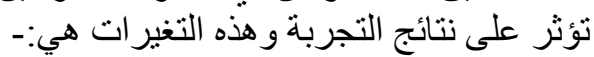
1 - العمر الزمني للطالبات بالأشهر. 2- القدرة العقلية (اختبار الذكاء).

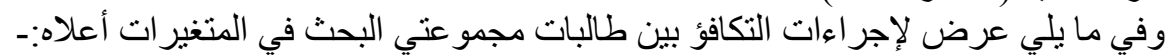

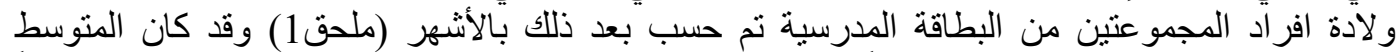
الحسابي للمجموعة التجريبية (152) شهراً وبلغ المنتوسط الحئ الحسابي للمجموعة الضابطة (150.4) شهراً و واستخدمت الباحثتين الاختبار الثاني (t-test) لعينتين مستقلين و ذللك للمقارنة بين المتوسط الحسابي للمجمو عتين

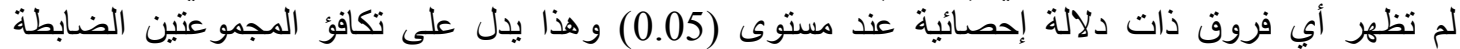
و التجريبية في متغير العمر الزمني والجة الجدول رقم (3) يوضح ذلكّ. 


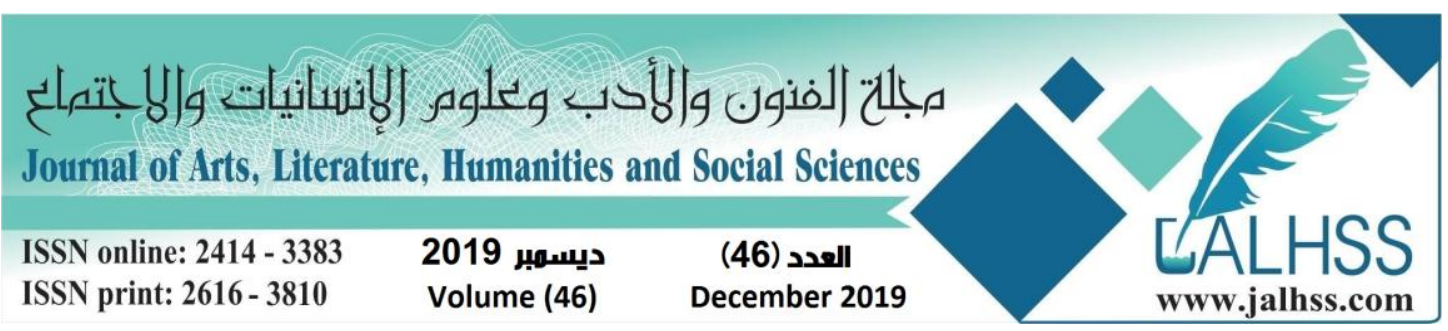

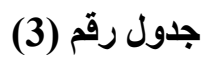

المتوسط الحسابي والأنحراف المعياري والتبايني والقيمة المحسوبة والجدولية لمجموعتي البحث في متغير

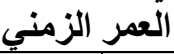

\begin{tabular}{|c|c|c|c|c|c|c|c|}
\hline الإحصائية & الحرية & الجدولية & المحسوبة & التباين & الحستبي & الفراد & المجموعة \\
\hline \multirow{3}{*}{ غند مسنوى دالة } & \multirow[t]{3}{*}{48} & \multirow[t]{3}{*}{2.000} & \multirow[t]{3}{*}{0.843} & 53.29 & 152 & 25 & التجريبية \\
\hline & & & & & & & \\
\hline & & & & 32.84 & 150.4 & 25 & الضابطة \\
\hline
\end{tabular}

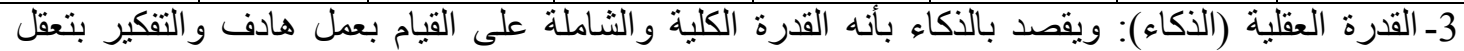

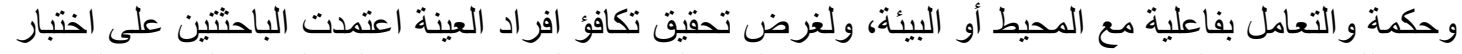

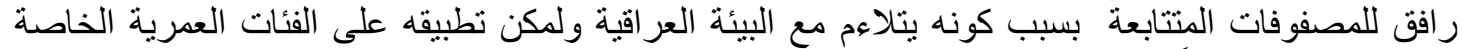

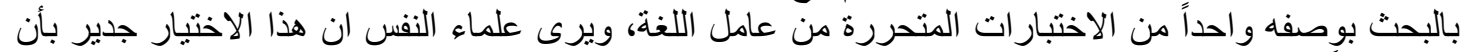

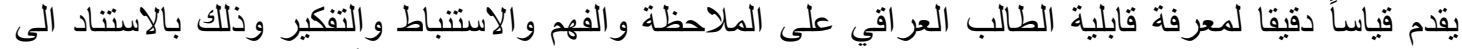

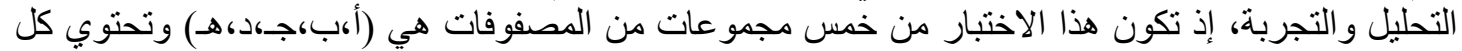

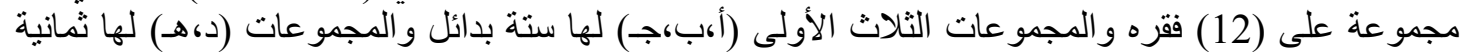

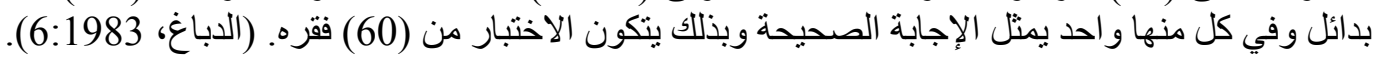

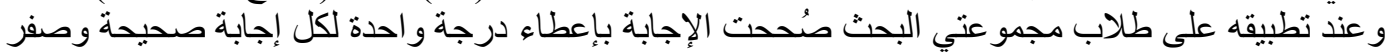

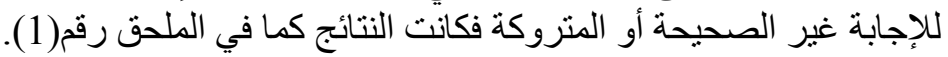

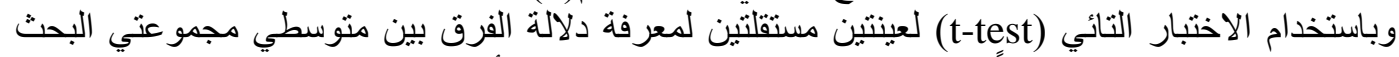

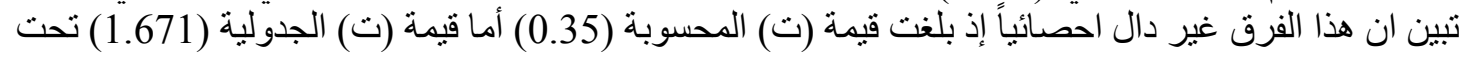

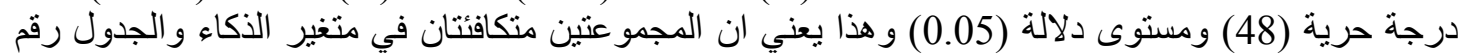

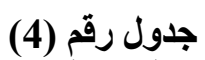

المتوسط الحسابي والانحراف المعياري والتباين والقيمة التائية المحسوبة والجدولية لمجموعتي البحث في متغير الأكاء

\begin{tabular}{|c|c|c|c|c|c|c|c|}
\hline الأحصائية & الدرجية & الجدولية & المحسوبة & التباين & الحسابي & علد العراد & المجموعة \\
\hline \multirow{2}{*}{ غستوى دالة عند 0.05} & \multirow[t]{2}{*}{48} & \multirow[t]{2}{*}{2.000} & \multirow[t]{2}{*}{0.034} & 64.48 & 29.12 & 25 & التجرييية \\
\hline & & & & 68.1 & 29.04 & 25 & الضابطة \\
\hline
\end{tabular}

رابعاً:- حفظ المتغيرات الاخلية: Regulation of Foreign Factors

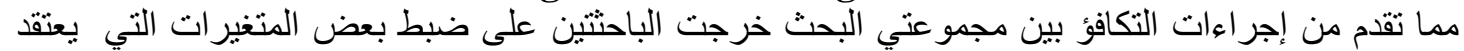

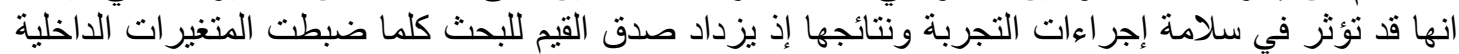

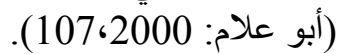
وفيما يلي عرض: الهذ لهذه المتغير ات وكيفية تفادي تأثير ها:-

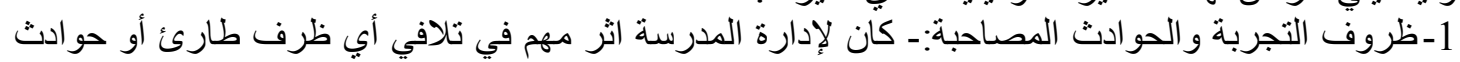

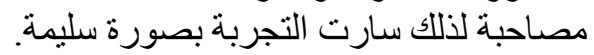
2- ادة القياس:- استعملت الباحثتين أداة قياس موحدة وهي الجئه اختبار اكتساب المفاهيم العلمية في نهاية التجربة

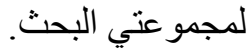
3-الاندثار التجريبي:- يعني الأثر الناتج عن نرك عدد من الطلاب عينة البحث أو تقاطعهم اثناء التجربة

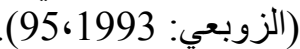
4ـ اثز الإجراءات التجريبية:- حاولت الباحثنين التقليل من اثر بعض العو امل التي قد تنوثر في سلامة التجربة 


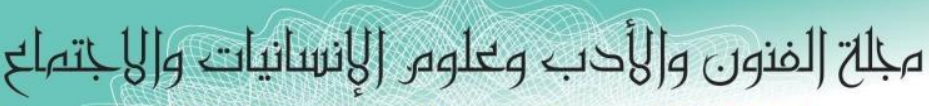
Journal of Arts, Literature, Humanities and Social Sciences

ISSN online: 2414 - 3383 ديسمبر 2019

ISSN print: 2616 - 3810 Volume (46)

العدد (46) December 2019

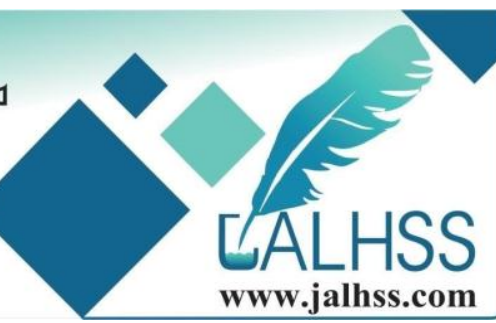

و هي:-

• سرية البحث:- قامت الباحثتين بالاتفاق مع إدارة المدرسة بالحفاظ على سرية التجربة وعدم اخبار الطلاب

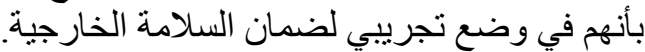
• المادة الدراسة:- ذُرست المجموعتان المادة الدارسة نفسها وهي الفصول الأربعة الأولى من كتاب الأحياء

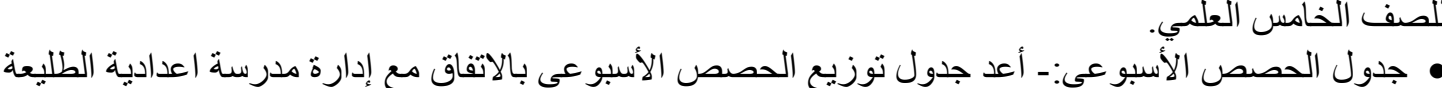

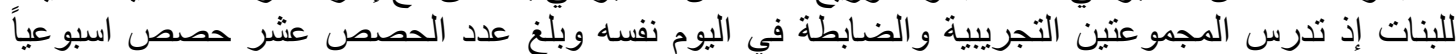
وبواقع خمس حصص لكل مجموعة موزعة على خلى خمسة أيام وقد درست فئل في يوم (الأحد، الأثنين، الثناثاء، الأربعاء، الخميس) و الجدول رقم (5) يوضح ذلكة فوزلك.

جدول رقم (5) جدول توزيع الحصص الأسبوعي لمجموعتي البحث

\begin{tabular}{|c|c|c|}
\hline الحصة & المجمو عة & اليوم \\
\hline الأاولى & الضنابطيبة & الأحد \\
\hline الأولىي & الضابطية & الأثنين \\
\hline الأناولى & الضابطية & الثلاثاء \\
\hline الأولىي & الضابطيبة & الأربعاء \\
\hline الأولىي & الضابطيبية & الخميس \\
\hline
\end{tabular}

5-بناية المدرسة:- طبقت التجربة في مدرسة و احدة وفي الصفوف نفسها في المدرسة.

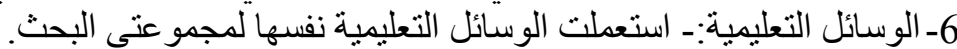
7ـ مدة التجربة:- تساوت مجمو عتا البحث في مدة البحث التي امتندت من يوم الأحد (2018/9/30) وحنى يوم الخميس (2018/12/28). (20)

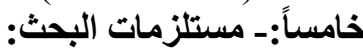

1-تحديد المادة الدراسية:- حددت المادة الدراسية من كتاب علم الأحياء المقرر تدريسية من وزارة التربية

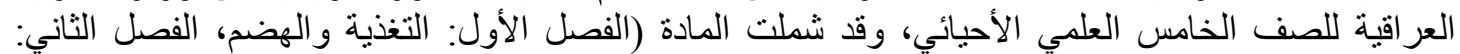

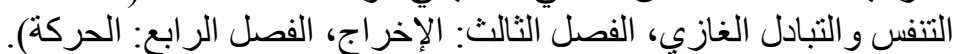

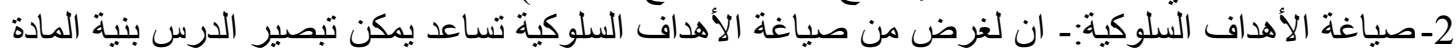

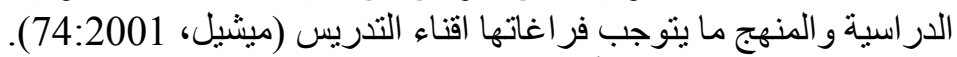

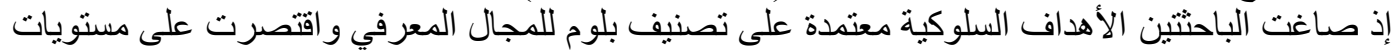

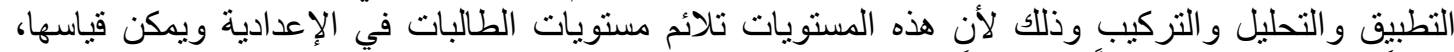

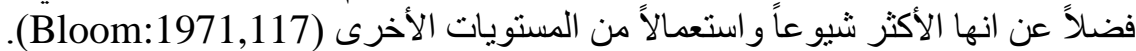

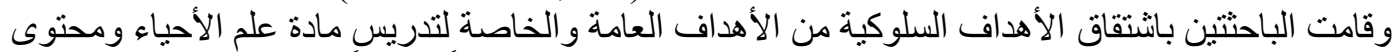

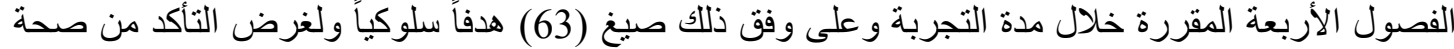

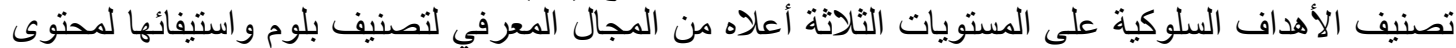

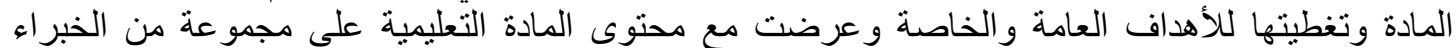

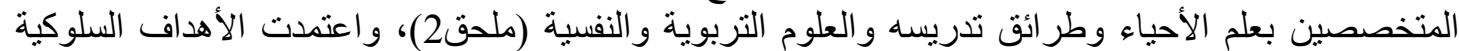

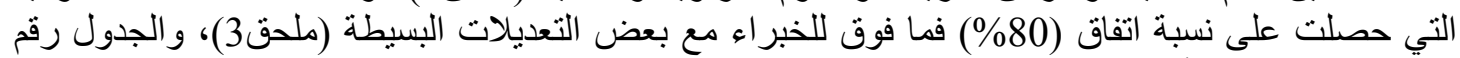

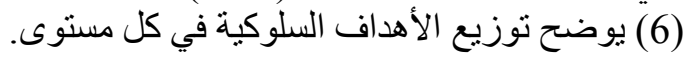




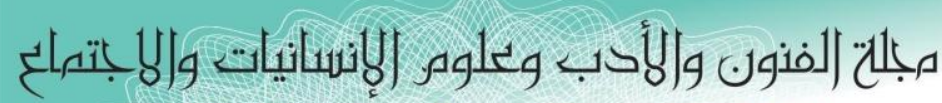
Journal of Arts, Literature, Humanities and Social Sciences

ISSN online: 2414 - 3383

ISSN print: $\mathbf{2 6 1 6}-\mathbf{3 8 1 0}$

\section{9 ديسمبر Volume (46)}

(46) العدد

December 2019
¿ALLHSS

www.jalhss.com

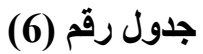

توزيع الأهداف السلوكية في المستويات الثلاث حسب الفصول الدراسية

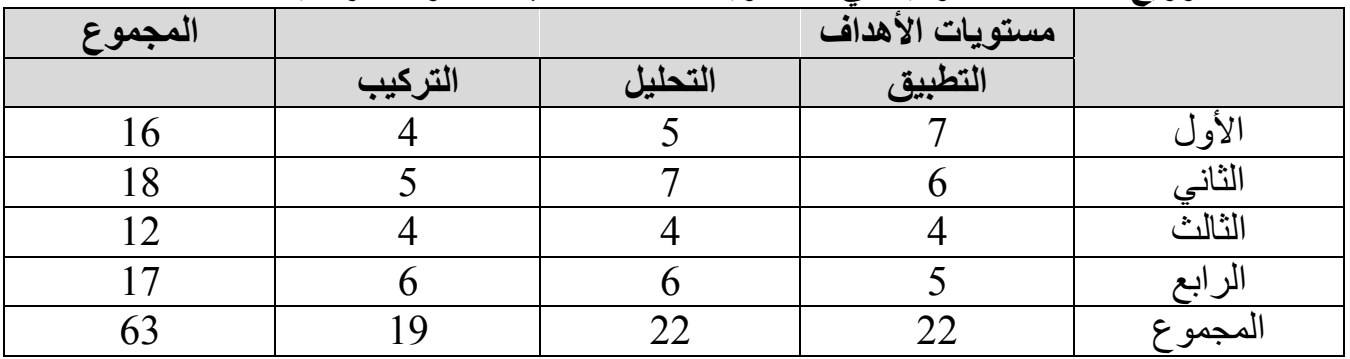

3ـ اعداد الخطط التنريسية: ويعني بالخطة التدريسية هي مجموعة الإجر اءات والتدابير السابقة التي يسعى المعلم

من خلالها القيام بعمل هادف (نشو التي: 1985، 1985 231).

وقامت الباحثتين بأعداد وتصميم خطط در اسية على وفئ النق انموذج رايجلوث و الطريقة الاعنيادية.

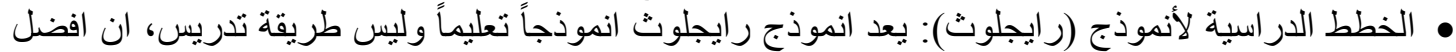

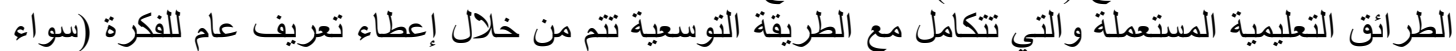

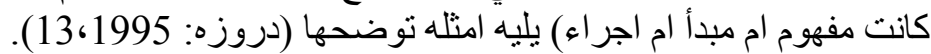

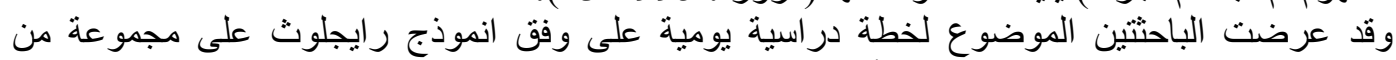

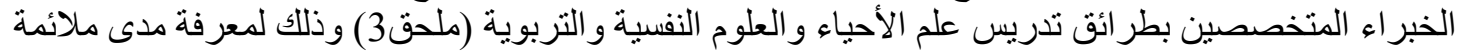

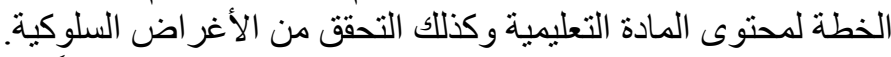

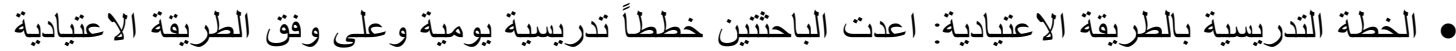

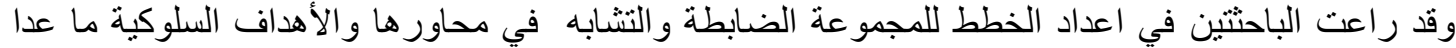

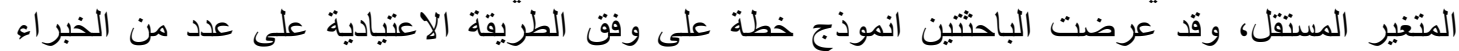

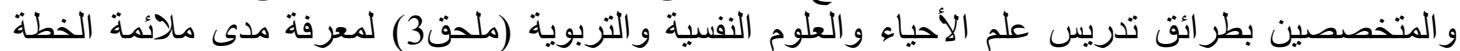

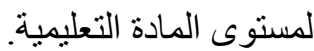

سادساً:- اعداد أداة البحث: Research Tool

يقصد بالاختبار: هو الإدارة التي توضح مدى تحقيق المادة الدراسية لأهدافها المحددة (Webstar: 1981,16).

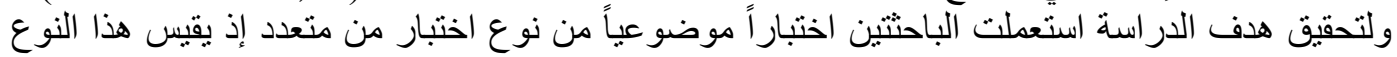

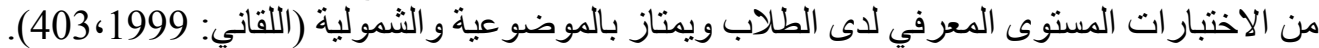

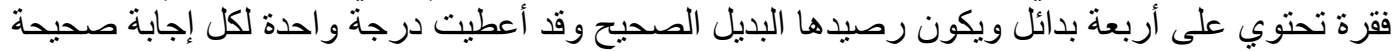
وصفر للك إجابة خاطئة ومثروكة وللتأكد من صلاحية فقرات اختبات التبار اكتساب المفاهيم العلمية اتبعت الباحثتين

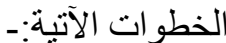

1-صدق الاختبار: و هو ان يقيس الاختبار ما وضع لقياسه (الورفي: 2000،75).

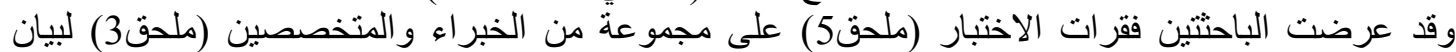

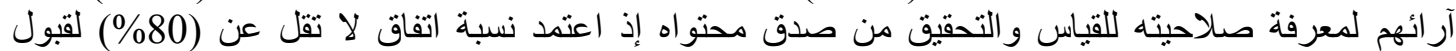
صلاحية كل فقرة من فقرات الاختبار عدا بعض الته من التعديلات البسيطة.

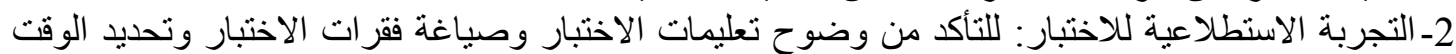

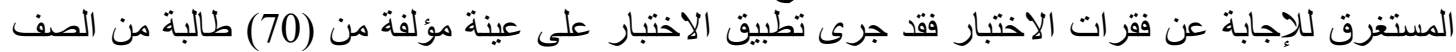

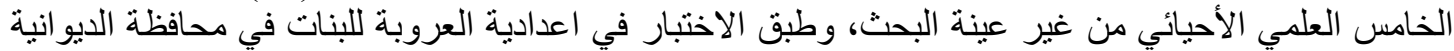

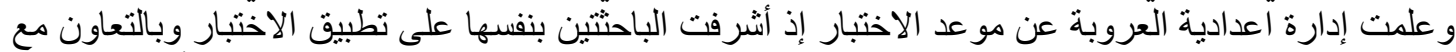

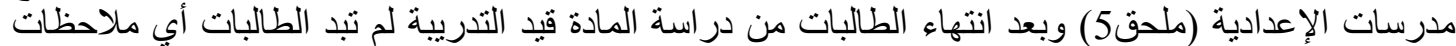

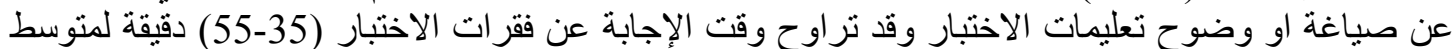
الإجابة (45) دقيقة

3- التحليل الإحصائي لفقرات الاختبار: الغرض من تحليل فقرات الاختبار هو اخراج الاختبار بصورة جيدة

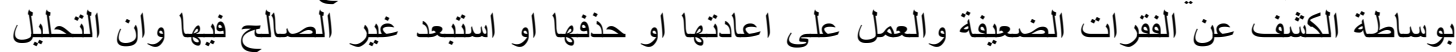


مبلحت (لفنون والأدب وعلوه الإنسانيات والبانتهاع

Journal of Arts, Literature, Humanities and Social Sciences

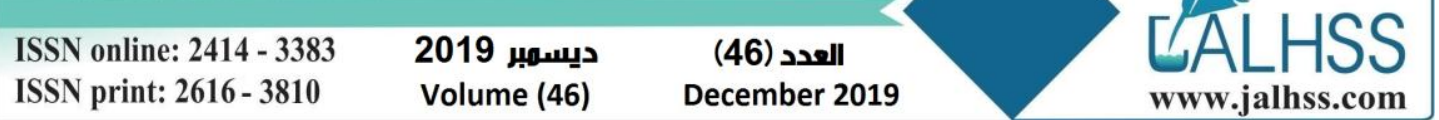

الإحصائي يساعد مصدم الاختبار على التشبث من ان فقرات الاختبار نراعي الفروق الفردية بين الطلاب ذوي

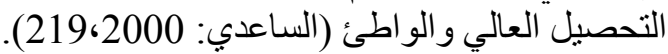

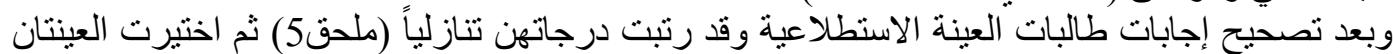

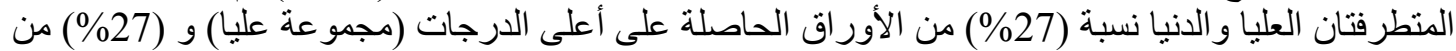

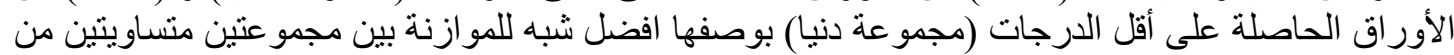

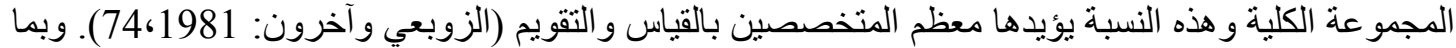

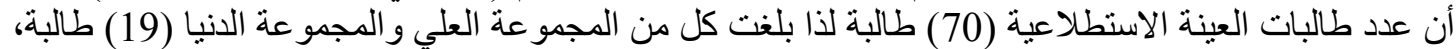

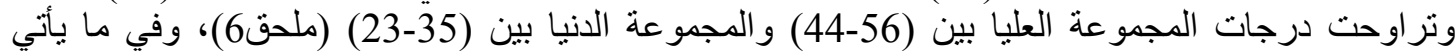

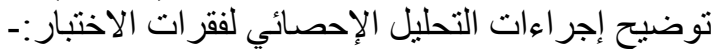

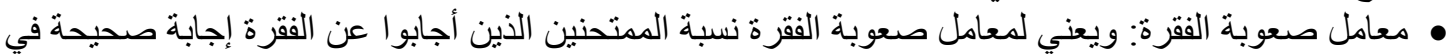

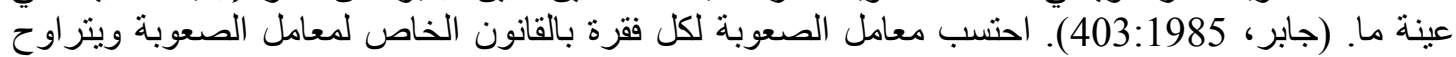

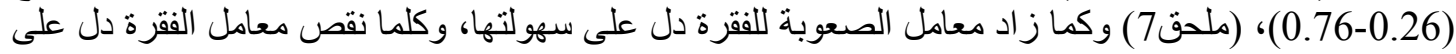

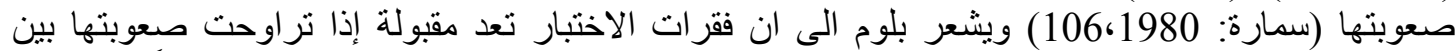

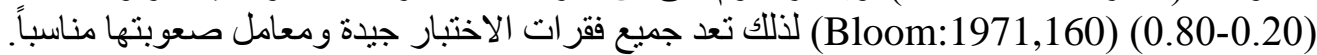

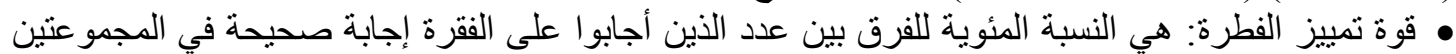

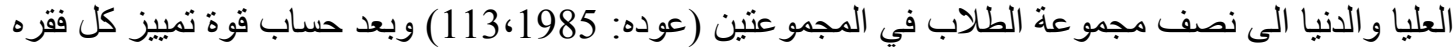

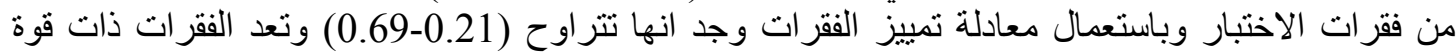

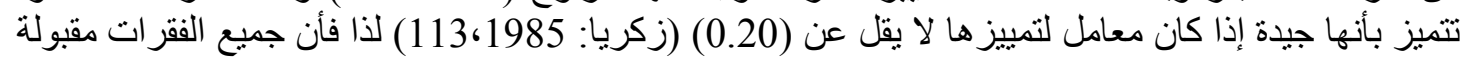

من حيث قوة التمبيز.

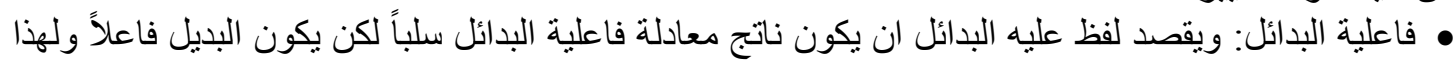

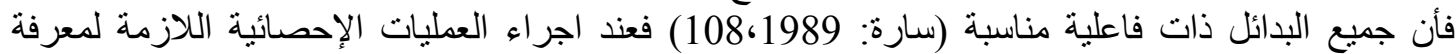

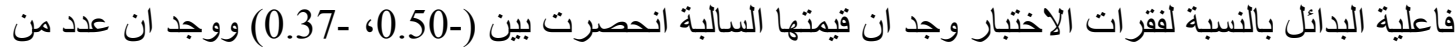

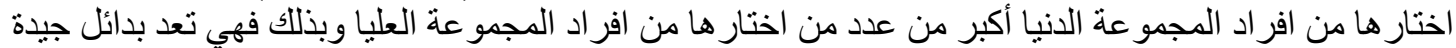

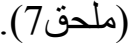

• ثبات الاختبار: هو مؤشر لمدى الاتساق والثبات الذي يقيس به الاختبار فما هو مصدم من اجل قياسه

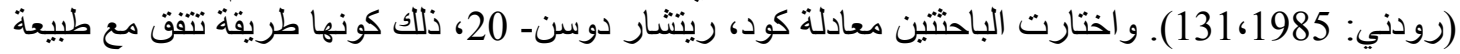

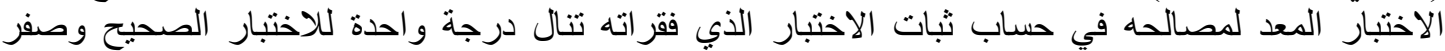
للاختبار غير الصحيح (يعقوب:

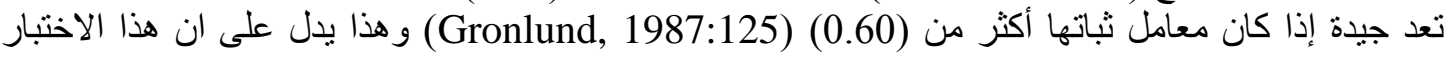

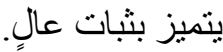

• الصيغة النهائية للاختبار: بعد الانتهاء من الإجراءات الإحصائية المتعلقة بفقرات الاختبار اصبح الأختبار

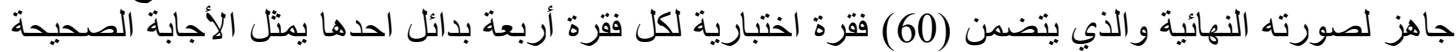

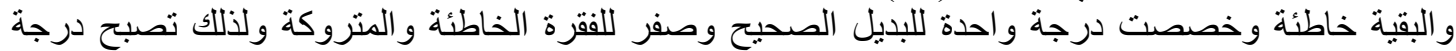

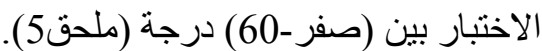
سابعاً:- إجراءات تبن تطبيق التجربة.

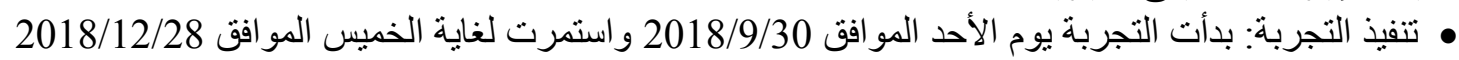

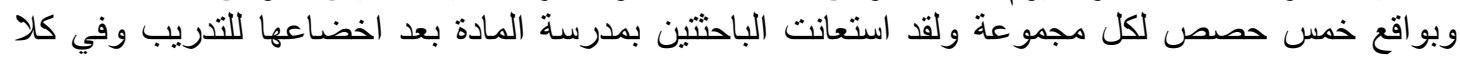

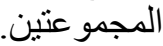

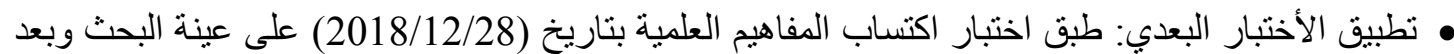

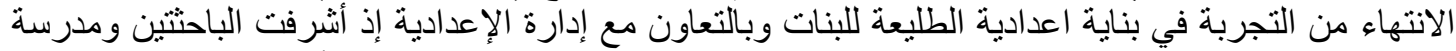

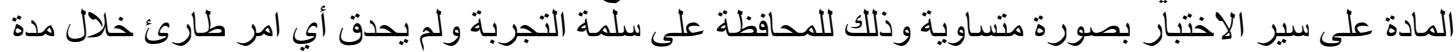
التجربة. • تصحيح إجابات الطالبات: جرت عملية تصحيح الأجابات وذلك بإعطاء درجة واحة للأجابة الصحيحة وصفر 


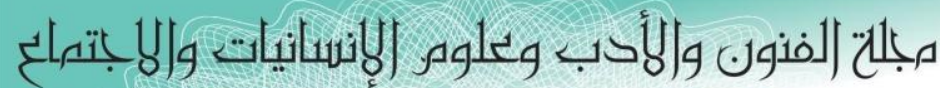

Journal of Arts, Literature, Humanities and Social Sciences

ISSN online: 2414 - 3383

ISSN print: $\mathbf{2 6 1 6}-\mathbf{3 8 1 0}$

ديس0بر 2019

Volume (46)
العدد (46)

December 2019
¿ALLHSS

www.jalhss.com

للأجابة الخاطئة و عوملت الأجابة المتروكة معاملة الأجابة الخاطئة.

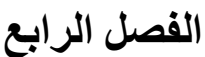 \\ عرض النتائج وتقبير ها}

يتضمن هذا الفصل عرض النتائج التي توصلت اليها الباحثتين بعد تطبيق اختبارات اكتساب المفاهيم

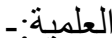

اولاً: عرض النتائج:- بعد نطبيق اختبار اكتساب المفاهيم العلمية على طالبات عينة البحث وتصحيح الأجابات وبعد اجر اء العمليات الأحصائية ظهرت النتائج و (جدول 7) يوضح الفئ ذللك.

جلول (7) (ل)

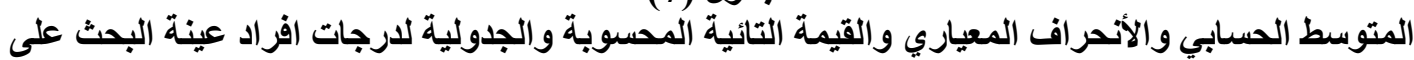

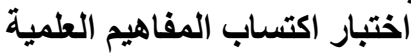

\begin{tabular}{|c|c|c|c|c|c|c|}
\hline الدلالة عند مستوى 0.05 & \multicolumn{2}{|c|}{ القيمة التائية } & التباين & المتوسط الحسابي & حجم العينة & المجموعة \\
\hline \multirow{2}{*}{ دالة تصلح المجموعة } & الجدولية & المحسوبة & 78.322 & 37.4 & 25 & التجرييية \\
\hline & 2.000 & 5.280 & 131.102 & 21.8 & 25 & الضابطة \\
\hline
\end{tabular}

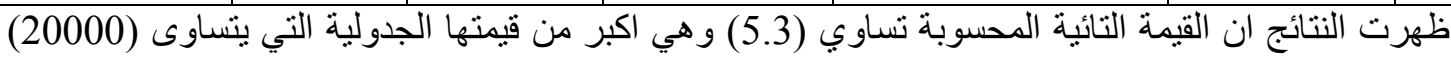

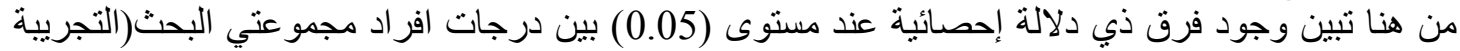

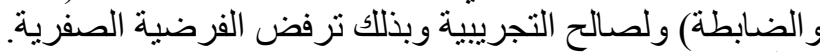

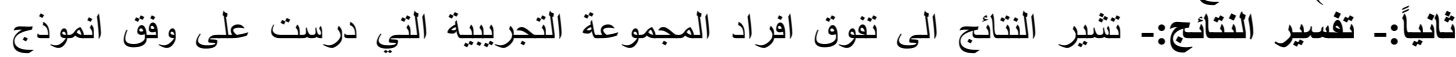
(رايجلوث) للنظرية التوسعية على افراد المجموعة الضابطة والتي درست بالطريقة الاعنيادية، ويمكن تفسير ذللك كالآتي. 1- ان التدريس بأستعمال أنموذج رايملوث يتضمن عرض إعادة الدراسية قبد البحث بصورة منسلسلة ومتدرجة

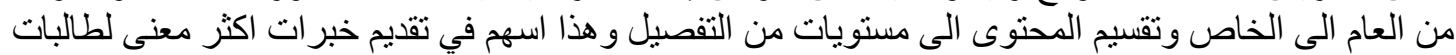
المجمو عة التجريبية.

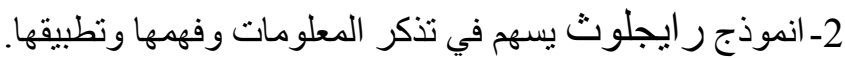

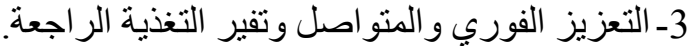

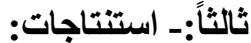

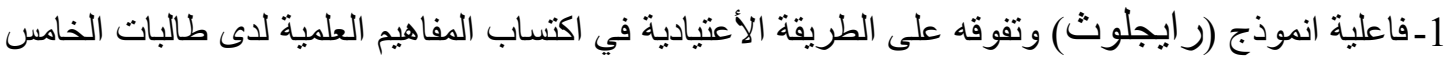

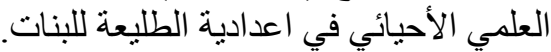
2- انموذج (رايجلوث) في تدريس علم الأحياء اثثتت فاعليته وذللك لأعتماده على خطوات اتل منظمة ومتساوية

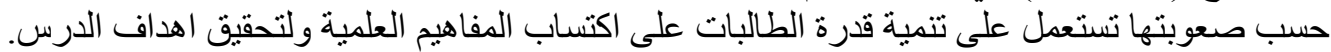

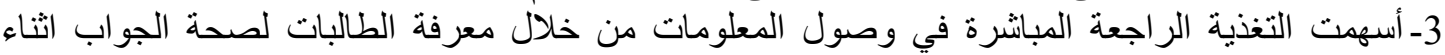

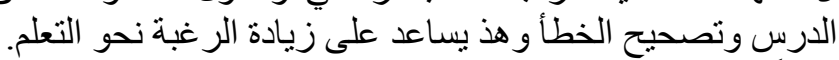

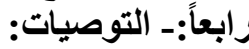
من خلال النتائج التي توصل التئ اليها البحث توصي الباحثتين بما يأتي:

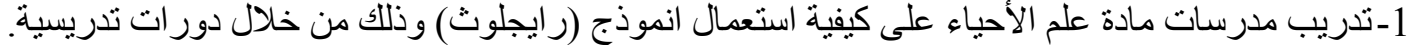

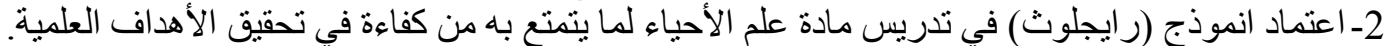

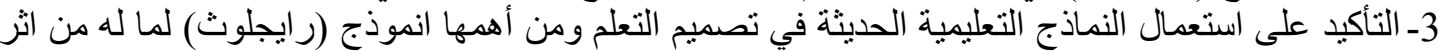
مهمه في تطوير العملية التعليمبة. 


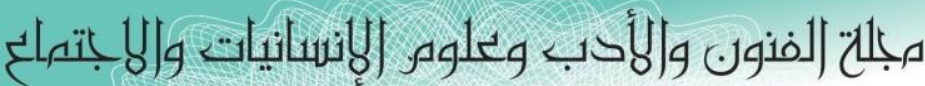

Journal of Arts, Literature, Humanities and Social Sciences

ISSN online: 2414 - 3383

ISSN print: 2616 - 3810

ديسمبر 2019

Volume (46)

العدد (46)

December 2019

1- استعمال النموذج (رايجلوث) في اكتساب المفاهيم العلمية من مراحل تعليمية أخرى مثل الدراسة الابتدائية و الثنانوية و الجامعية.

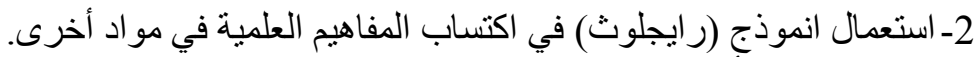
3- اجر اء در اسة لأحد النماذج التعليمية ومقارنتها مع انموذج (ر ايجلوث).

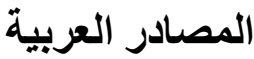
1- أبو علام، صلاح العريلة الدين محمود (2000): القياس و التقويم التربوي و النفسي اساسياته وتطبيقاته وتوجيهاته المعاصرة، دار الفكر العبي، القاهرة. 2- أبو ناصر، فتحة التحي محمد (2008): مدخل الى الإدارة التربوية النظريات المهارات، دار المسيرة للنشر

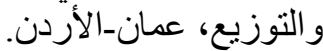
3- الآلوسي، السيد محمود سكري (1984): عقوبات الحرب الحئ في جاهليتها وحدود المعاصي التي برتكبها الفهم،

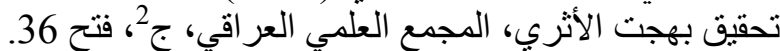

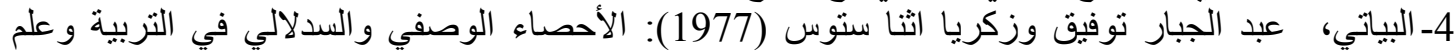

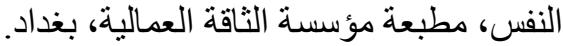

5-جابر، عبد الحميد جابر وآخرون (1985): مهار العات التدريس، دار النهضة النة العربية، القاهرة.

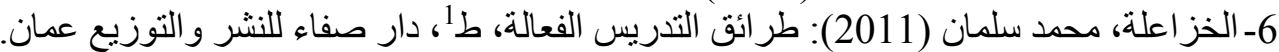

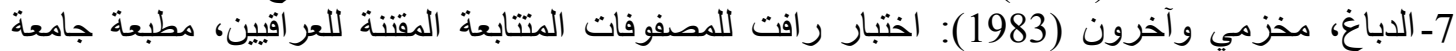

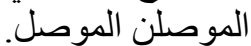
8-دروزه، افنان نظرير (1988): نماذج تنظيم محتوى المناهج، مجلة جامعة دمشق للعلوم الأنسانية، العدد

9-دروزة، افنان نظير (1995): إجراءات تصميم المناهج، ط، جامعة النجاح الوطنية، مركز التوثيق للنشر

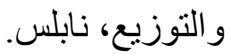
10- دروزة، افنان نظير (2000): النظرية في التدريس وترجمتها علمياً، دار الثروق للنشر و التوزيع، عمان-

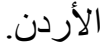
11- الاليمي، خالد جمال حمدي(2005): اثر استخدام انموذج ميرل ورايملوث الموسيع في في تحصيل طلاب

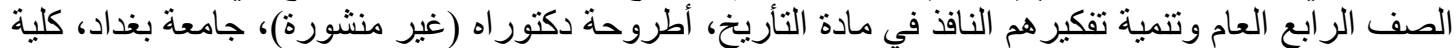

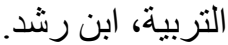
12-رودني، دوران (1985): اساسيات القياس و التقويم في تدريس العلوم، نرجمة محمد سعيد صبار ، جامعة اليرموك، المكتبة الوطنية، عمان.

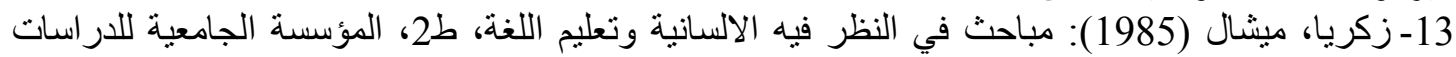

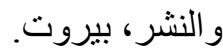
14- الزوبعي، عبد الخليل إبراهيم ووهب مجيد البيد الكبيسي (1993): علاقة التفكر الأستدلالي لدى طلبة الجامعة

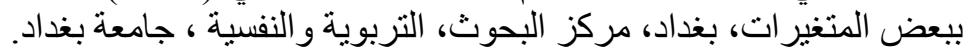
15- الساعدي، كريم خو اس (2000): برنامج تعليمي لتنمية أداء طلبة قسم التربية الفنية، رسالة ماجستير (غير

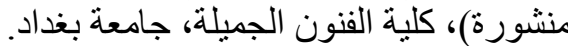
16- سلامة، عادل (2004): تنمية المفاهيم و المهار ات العلمبة وطية وطرق تدريسها، ط1، دار الفكيرة الفيرة، عمان-الأردن.

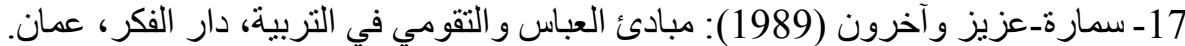

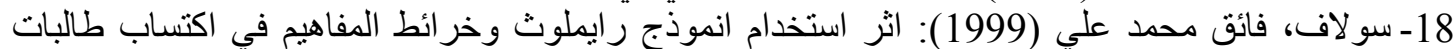

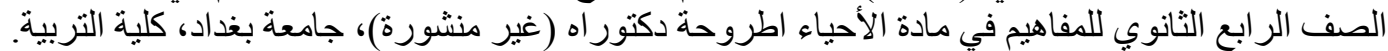

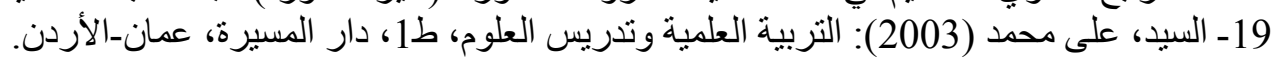

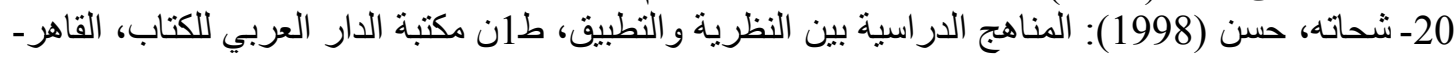


مبلحت (لفنون والأذب وعلوه الإنسانيات والابتهماع

Journal of Arts, Literature, Humanities and Social Sciences

ISSN online: 2414 - 3383

ISSN print: $\mathbf{2 6 1 6}$ - $\mathbf{3 8 1 0}$

Volume (46)

العدد (46)

December 2019

21- عبد العزيز ، إبراهيم (2001): فعالية تنظيم محتوى منهج العلوم وفق نظريين الإنين جانبية الهرمية ور ايملوث

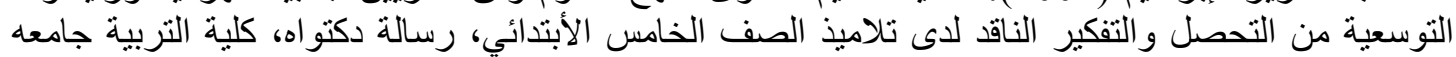

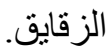

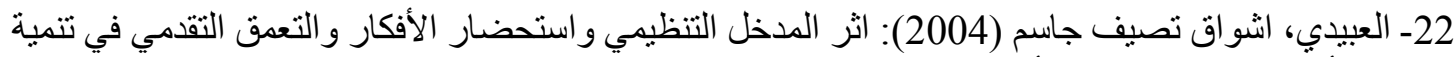

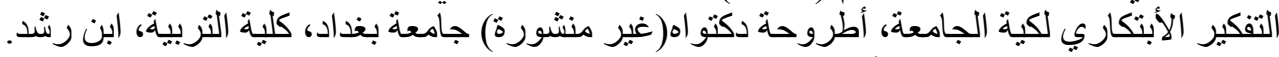

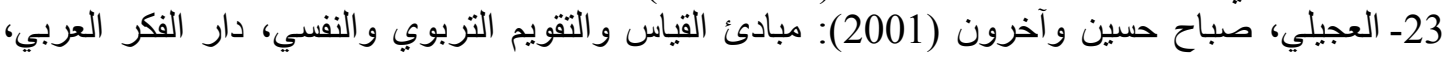

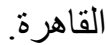
24- عقل، أنور (2001): نحو تقويم أفضل، دار النهضة العربية، بيروت_لبنان.

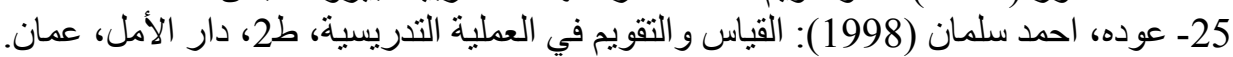

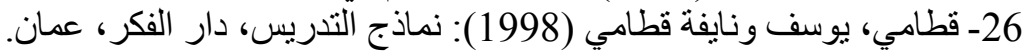

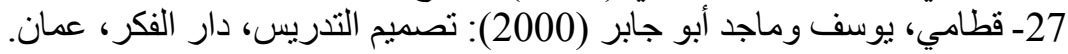

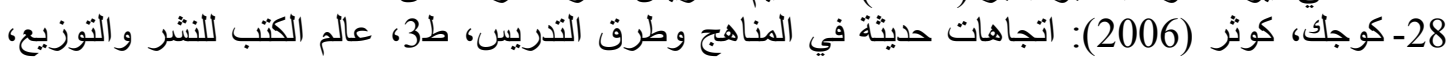

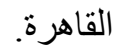
29- اللقاني، احمد حسين و على احمد الجمل (1999): معجم المصطلحات التربوية المعروفة في المناهج وطرق

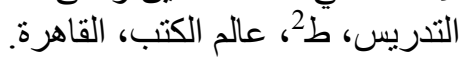
30ـ اللولو، فتحية واحسان الأغا (2006): تدريس العلوم في التعليم العام، ط، الجامعة الأسلامية، غزة-

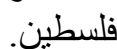
31- مجلة العلوم الأنسانية والأجتماعية (2012)، العدد الثامن.

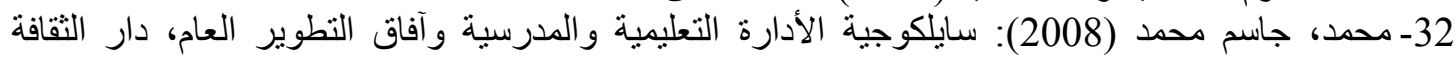

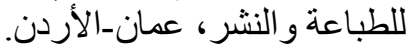
33- مر عي، توفيق احمد ومحمج محمود الحيلة (2000): طر ائق التدريس العامة، دار المسيرة، عمان.

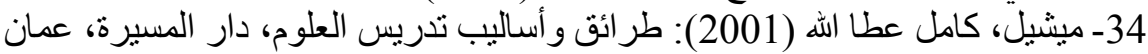

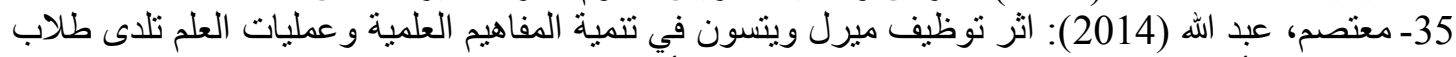

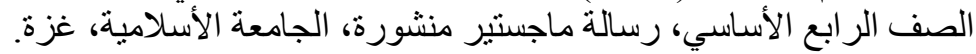

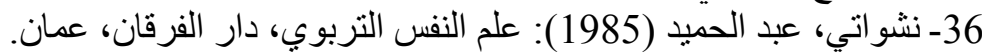

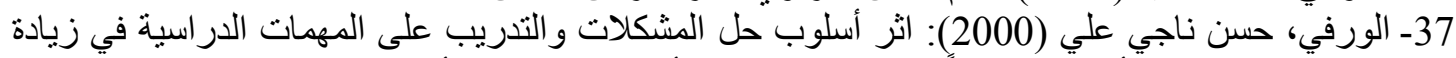

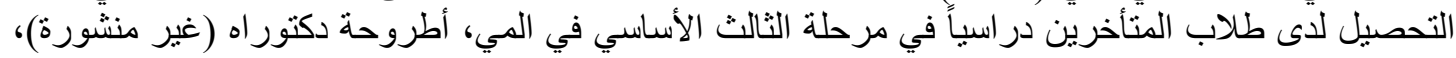
بغداد، الجامعة المستنصرية، كلية التربية.

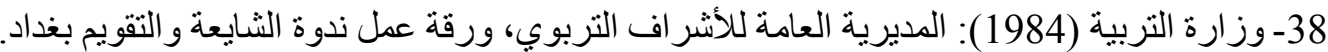

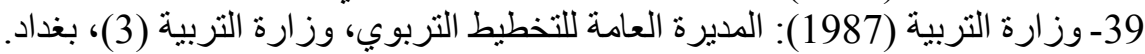

\section{References}

1- Abu Allam, Salah El-Din Mahmoud (2000): Measurement and Evaluation of Educational and Psychological Basics, Applications and Contemporary Directives, Dar Al-Fikr Al-Abi, Cairo.

2- Abu Nasser, Fathi Mohammed (2008): Introduction to Educational Administration Theories Skills, Al-Masirah Publishing \& Distribution House, Amman-Jordan.

3. Al-Alousi, Mr. Mahmoud Sukkari (1984): Penalties of war in ignorance and the limits of sins committed by understanding, Bahgat archaeological investigation, Iraqi Scientific Council, vol. 2, Fatah 36. 


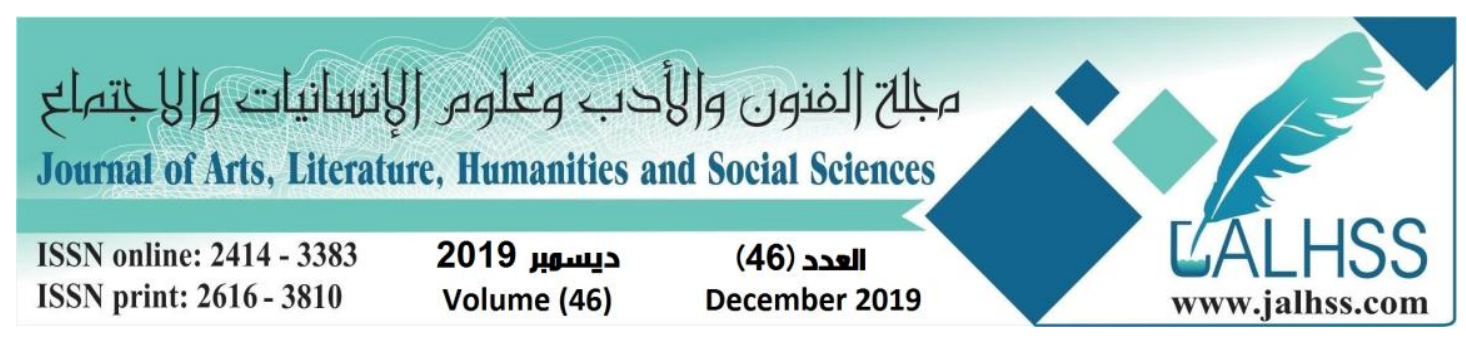

4. Al-Bayati, Abdul Jabbar Tawfiq and Zakariya Athna Stos (1977): Descriptive and Descriptive Statistics in Education and Psychology, Al Thaqa Workers Press, Baghdad.

5 - Gaber, Abdel Hamid Gaber and others (1985): teaching skills, the Arab Renaissance House, Cairo.

6- Al-Khazaleh, Mohammed Salman (2011): Effective Teaching Methods, Dar Safaa for Publishing and Distribution Amman.

7. Al-Dabbagh, Makhzami et al. (1983): Rafat Test for Sequential Matrices for Iraqis, Mosul University Press, Mosul.

8- Darwazah, Afnan Nazeer (1988): Curriculum Content Organization Models, Damascus University Journal for Humanities, No. 13.

9- Darwazah, Afnan Nazeer (1995): Curriculum Design Procedures, An-Najah National University, Documentation Center for Publishing and Distribution, Nablus.

Darwazah, Afnan Nazeer (2000): Theory of Teaching and its Scientific Translation, Dar Al-Shorouk for Publishing and Distribution, Amman-Jordan.

11- Al-Dulaimi, Khaled Jamal Hamdi (2005): The Effect of Using Merle and Reemluth's Extended Model in the Achievement of Fourth Grade Students and Developing their Effective Thinking in History, PhD Thesis (Unpublished), Baghdad University, College of Education, Ibn Rushd.

12- Rodney, Duran (1985): Fundamentals of Measurement and Evaluation in Teaching Science, Translated by Mohammed Saeed Sabbar, Yarmouk University, National Library, Amman.

13- Zakaria, Michel (1985): Investigations in the consideration of linguistics and language teaching, University Foundation for Studies and Publishing, Beirut.

14- Al-Zobaie, Abdul Khalil Ibrahim and Wahab Majeed Al-Kubaisi (1993): The relationship of inference reasoning among university students with some variables, Baghdad, Research Center, Educational and Psychological, University of Baghdad.

15- Saadi, Karim Khawas (2000): an educational program to develop the performance of students of the Department of Art Education, Master Thesis (unpublished), College of Fine Arts, University of Baghdad.

16- Salama, Adel (2004): Development of scientific concepts and skills and methods of teaching them, Dar Al-Fakir, Amman-Jordan.

Samara-Aziz et al. (1989): The Principles of Abbas and Taqumi in Education, Dar AlFikr, Amman.

18- Sulaf, Faek Mohammed Ali (1999): The Effect of Using Raymuth Model and Concept Maps in the Fourth Grade Students Acquisition of Concepts in Biology, Ph.D. Thesis (Unpublished), University of Baghdad, College of Education.

19- Mr. Ali, Ali (2003): Scientific Education and Science Teaching, Dar Al-Masirah, Amman-Jordan.

20- Shehata, Hassan (1998): The Curriculum Between Theory and Practice, 1st Edition, Dar Al-Arabi Book Library, Cairo, Egypt. 


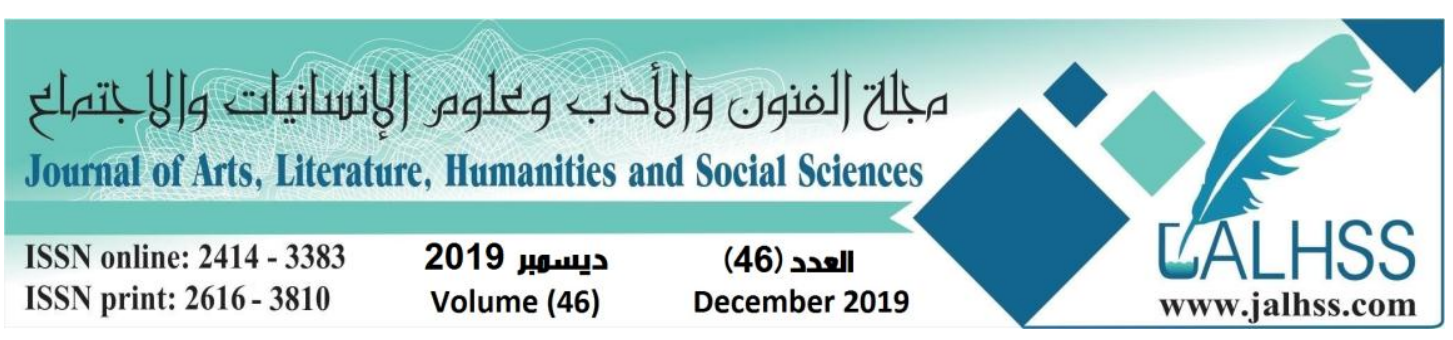

21- Abdul Aziz, Ibrahim (2001): Effectiveness of organizing the content of the science curriculum according to the theoretical hierarchical and Raymuth theoretical expansions from the collection and critical thinking of the fifth grade pupils, thesis, Faculty of Education, Zagazig University.

22- Al-Obeidi, Ashwaq Tasif Jasim (2004): The Effect of Organizational Approach, Evolution of Ideas and Progressive Depth in Developing Innovative Thinking of the University College, Ph.D. Dissertation (Unpublished) University of Baghdad, College of Education, Ibn Rushd.

23. Al-Ajili, Sabah Hussein and others (2001): Principles of educational and psychological evaluation and evaluation, Dar Al-Fikr Al-Arabi, Cairo.

24- Aqel, Anwar (2001): Towards a Better Evaluation, Dar Al-Nahda Al-Arabiya, Beirut, Lebanon.

25- Odeh, Ahmad Salman (1998): Measurement and Evaluation in the Teaching Process, 2nd edition, Dar Al-Amal, Amman.

26- Qatami, Yusuf and Nayfeh Qatami (1998): Teaching Models, Dar Al-Fikr, Amman.

27- Qatami, Yousef and Majed Abu Jaber (2000): Teaching Design, Dar Al-Fikr, Amman.

28- Kojak, Kawther (2006): Recent Trends in Curricula and Teaching Methods, 3rd Edition, Books World for Publishing and Distribution, Cairo.

29. Allagani, Ahmed Hussein and Ali Ahmed El-Gamal (1999): Glossary of educational terms known in the curricula and teaching methods, the world of books, Cairo.

30- Lulu, Fathia and Ihsan al-Agha (2006): Teaching Science in General Education, 2nd floor, Islamic University, Gaza-Palestine.

31. Journal of Humanities and Social Sciences (2012), No. 8.

32- Mohammed, Jassim Mohammed (2008): Syllogism of Educational and School Administration and Prospects of Public Development, Dar Al Thaqafa for Printing and Publishing, Amman-Jordan.

33- Marei, Tawfeeq Ahmad and Mahjoud Mahmoud Al-Haila (2000): General Teaching Methods, Dar Al-Masira, Amman.

34- Michel, Kamel Atallah (2001): Methods and Methods of Teaching Science, Dar Al-Masira, Amman

35- Mu'tasim, Abdullah (2014): The Impact of Merle Whitson's Employment in Developing Scientific Concepts and Science Processes, Fourth Grade Students Delivered, Master Thesis, Islamic University, Gaza.

36- Nashawati, Abdul Hamid (1985): Educational Psychology, Dar Al-Furqan, Amman.

37- Al-Warfi, Hassan Naji Ali (2000): The Effect of Problem Solving and Training on Study Tasks on Increasing Achievement among Students in the Third Basic Stage in May, Ph.D. Dissertation (Unpublished), Baghdad, Mustansiriya University, College of Education. 


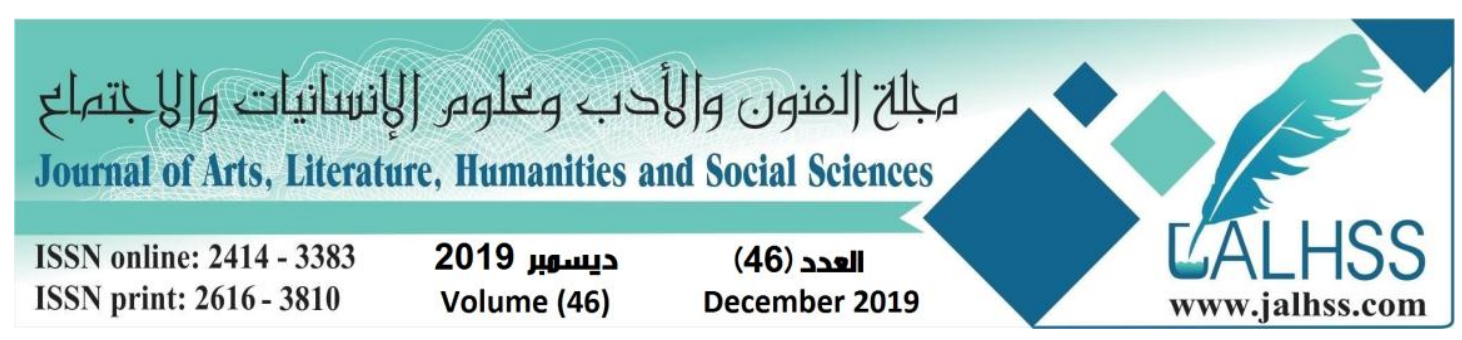

38 - Ministry of Education (1984): General Directorate of Educational Supervision, working paper symposium Alshaya and evaluation Baghdad.

39- Ministry of Education (1987): Director General of Educational Planning, Ministry of Education, 3 Baghdad.

40- Bloom B.S and Madaus, G.F (1971): Hard Bookon for motive an summative Evaluation of student learning, New York, Me Graw-hill, New York.

41- Gronlund ,N(1987): Mea surm-ent and Evaluation in teaching, $4^{\text {th }}$ ed, New York Macmillan.

42- Regolith C.M (1981): An Investi-gution of the effects of Alter native strategies for sequencing I nstruction on Basic skill, ERIC Document, ED, No (288-512).

43- Wilson, B. and col,p (1992): Acritical Review of Elaboration Theory Education Technology Research and Development (v40,N3,pp63-79).

44- Seels, Barbara (1997):Taxonomic Issue and the development if theory in Instructional Technology, Educational Technology, vol. (16), No(5). 